\title{
Airborne DOAS measurements in Arctic: vertical distributions of aerosol extinction coefficient and $\mathrm{NO}_{2}$ concentration
}

\author{
A. Merlaud ${ }^{1}$, M. Van Roozendael ${ }^{1}$, N. Theys ${ }^{1}$, C. Fayt $^{1}$, C. Hermans ${ }^{1}$, B. Quennehen ${ }^{2}$, A. Schwarzenboeck ${ }^{2}$, \\ G. Ancellet ${ }^{3}$, M. Pommier ${ }^{3}$, J. Pelon ${ }^{3}$, J. Burkhart ${ }^{4}$, A. Stohl ${ }^{4}$, and M. De Mazière ${ }^{1}$ \\ ${ }^{1}$ Belgian Insitute for Space Aeronomy (BIRA-IASB), Avenue Circulaire 3, 1180 Brussels, Belgium \\ ${ }^{2}$ Laboratoire de Météorologie Physique, Université B. Pascal, CNRS, France \\ ${ }^{3}$ UPMC Univ. Paris 06; Université Versailles St-Quentin; CNRS/INSU, UMR8190, LATMOS-IPSL, Paris, France \\ ${ }^{4}$ Norwegian Institute for Air Research (NILU), Instituttveien 18, 2007 Kjeller, Norway
}

Received: 25 February 2011 - Published in Atmos. Chem. Phys. Discuss.: 4 May 2011

Revised: 10 August 2011 - Accepted: 23 August 2011 - Published: 7 September 2011

\begin{abstract}
We report on airborne Differential Optical Absorption Spectroscopy (DOAS) measurements of aerosol extinction and $\mathrm{NO}_{2}$ tropospheric profiles performed off the North coast of Norway in April 2008. The DOAS instrument was installed on the Safire ATR-42 aircraft during the POLARCAT-France spring campaign and recorded scattered light spectra in near-limb geometry using a scanning telescope. We use $\mathrm{O}_{4}$ slant column measurements to derive the aerosol extinction at $360 \mathrm{~nm}$. Regularization is based on the maximum a posteriori solution, for which we compare a linear and a logarithmic approach. The latter inherently constrains the solution to positive values and yields aerosol extinction profiles more consistent with independently measured size distributions. We present results from two soundings performed on 8 April 2008 above $71^{\circ} \mathrm{N}, 22^{\circ} \mathrm{E}$ and on 9 April 2008 above $70^{\circ} \mathrm{N}$, $17.8^{\circ} \mathrm{E}$. The first profile shows aerosol extinction and $\mathrm{NO}_{2}$ in the marine boundary layer with respective values of $0.04 \pm 0.005 \mathrm{~km}^{-1}$ and $1.9 \pm 0.3 \times 10^{9} \mathrm{molec} \mathrm{cm}^{-3}$. A second extinction layer of $0.01 \pm 0.003 \mathrm{~km}^{-1}$ is found at $4 \mathrm{~km}$ altitude where the $\mathrm{NO}_{2}$ concentration is $0.32 \pm 0.2 \times 10^{9}$ molec $\mathrm{cm}^{-3}$. During the second sounding, clouds prevent retrieval of profile parts under $3 \mathrm{~km}$ altitude but a layer with enhanced extinction $\left(0.025 \pm 0.005 \mathrm{~km}^{-1}\right)$ and $\mathrm{NO}_{2}$ $\left(1.95 \pm 0.2 \times 10^{9} \mathrm{molec} \mathrm{cm}^{-3}\right)$ is clearly detected at $4 \mathrm{~km}$ altitude.

From CO and ozone in-situ measurements complemented by back-trajectories, we interpret the measurements in the free troposphere as, for the first sounding, a mix between stratospheric and polluted air from Northern Europe and for
\end{abstract}

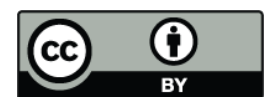

Correspondence to: A. Merlaud (alexis.merlaud@aeronomie.be) the second sounding, polluted air from Central Europe containing $\mathrm{NO}_{2}$. Considering the boundary layer measurements of the first flight, modeled source regions indicate closer sources, especially the Kola Peninsula smelters, which can explain the $\mathrm{NO}_{2}$ enhancement not correlated with a $\mathrm{CO}$ increase at the same altitude.

\section{Introduction}

Despite its remoteness, the Arctic troposphere is affected by trace gases and aerosols emissions from mid-latitude regions. The Arctic Haze phenomenon, observed since the 1950s, is a visible manifestation of this long-range transport (Shaw, 1995). The effects of this pollution are specific to the area and may explain part of the enhanced warming observed there. Indeed, the dry Arctic air makes the area more sensitive to the increase in non-water greenhouse gases. Furthermore, above the high-albedo snow and ice surfaces, aerosols - even if only weakly absorbing - can lead to a warming, contrary to their global cooling effect (Law and Stohl, 2007, and references therein). Climate change may further modify the arctic tropospheric composition. For instance, if the summer sea ice continues its decline, ship traffic through the Northern passages will become an important source of aerosols and $\mathrm{NO}_{\mathrm{x}}$, the latter also driving an increase in tropospheric ozone (Granier et al., 2006). Quantifying such phenomena requires an accurate knowledge of the Arctic troposphere. In this paper we present airborne DOAS measurements of the vertical distribution of aerosol extinction coefficient and $\mathrm{NO}_{2}$ concentration off the North coast of Norway during the POLARCAT-France spring campaign.

Published by Copernicus Publications on behalf of the European Geosciences Union. 
Differential Optical Absorption Spectroscopy (DOAS) has been widely used for atmospheric research (Platt and Stutz, 2008). First applied to the retrieval of stratospheric gas columns using zenith-sky observations of solar scattered light, the technique has been recently extended to the detection of tropospheric gases by means of observations along multiple viewing directions (Multi-Axis DOAS; Hönninger et al., 2004). Such measurements also yield information on the vertical distribution of the gases (Wittrock et al., 2004). The possibility to extend this profiling technique to aerosol extinction was demonstrated (Wagner et al., 2004; Friess et al., 2006) and implemented by several groups (Irie et al., 2008; Clémer et al., 2010). The approach uses the $\left(\mathrm{O}_{2}\right)_{2}$ collision complex, referred to hereafter as $\mathrm{O}_{4}$, which has strong absorption bands in the UV-Visible range. Aerosols affect DOAS measurements of any absorber by modifying the light path but the effect can be isolated for $\mathrm{O}_{4}$ since its vertical distribution is well-known. The vertical resolution retrieved from the ground-based measurements remains poor however; typically two independent layers can be retrieved close to the surface and only little information in the free troposphere. On the other hand, satellite-borne instruments using UVvisible limb radiance measurements date back to the Solar Mesosphere Explorer (SME, Mount et al., 1984). This geometry provides a good vertical resolution in the stratosphere, but for tropospheric studies from satellites, nadir-looking instruments have to be used, such as the Ozone Monitoring Instrument (OMI, Levelt et al., 2006), which are only sensible to the total tropospheric column. A way to overcome this limitation relies on operating a DOAS instrument from aircraft, combining the multi-axis measurements at different altitudes. The Airborne Multi-Axis DOAS (AMAXDOAS) instrument, recording simultaneously scattered-light spectra at different angles from an airplane, has already measured $\mathrm{NO}_{2}$ vertical distributions (Bruns et al., 2006) in a polluted region. Prados-Roman et al. (2011) have used another airborne set-up with a single line-of-sight, parallel to the ground, and derived $\mathrm{BrO}$ Arctic profiles from the ascent of the aircraft. The instrument developed in this work, namely the Airborne Limb Scanning DOAS (ALS-DOAS), combines the two setups with a single line-of-sight scanning the horizon continuously.

In the next section we describe the technical aspects of the ALS-DOAS instrument and its operation on the Safire ATR42 during the POLARCAT-France spring campaign. The methods used for the data analysis, i.e. the DOAS settings, radiative transfer modeling, inversion schemes and error budget are presented in Sect. 3. These methods are applied in Sect. 4 to two soundings performed during the flights on 8 and 9 April 2008. Retrieved extinctions are compared with Mie-scattering calculations performed on aerosol size distributions measured in situ. In Sect. 5, we interpret these results using ancillary measurements of $\mathrm{CO}$ and ozone mixing ratios, as well as backward trajectories calculations.

\section{The ALS-DOAS instrument and its operation during a POLARCAT campaign}

\subsection{Instrumental description}

The Airborne Limb Scanning DOAS (ALS-DOAS) was developed at the Belgian Institute for Space Aeronomy (BIRAIASB) and first used during the POLARCAT campaign. Based on a grating spectrometer, it records limb-scattered sky light spectra at several angles around the horizon, following the Multi-axis DOAS principle (Hönninger et al., 2004).

Figure 1 shows the ALS-DOAS installed in the SAFIRE ATR-42 aircraft. The entrance optic is composed of a $1^{\circ}$ field-of-view telescope focusing the light into an optical fiber. A 5-cm black paperboard baffle limits the stray light at the entrance of the telescope. This telescope, standing behind a BK-7 glass port, is mounted on a stepper-motor axis and scans continuously between $-5^{\circ}$ and $5^{\circ}$ by steps of $1^{\circ}$. Between the fiber and the spectrometer, a Jobin Yvon optical interface matches the fiber and spectrometer numerical apertures. The spectrometer is a SpectraPro-150 (imaging Czerny-Turner set-up, $150 \mathrm{~mm}$ focal length) from Acton Research Corporation, with a $100 \mu \mathrm{m}$ entrance slit. The spectral range is $330-450 \mathrm{~nm}$, with a resolution of $0.4 \mathrm{~nm}$ full width at half maximum (UV) to $0.6 \mathrm{~nm}$ (visible). A custom Terimide 7 thermal insulation limits the thermal effects on the spectrometer and the matching interface. The detector, a back-illuminated Pixis CCD $2048 \times 512$ pixels $^{2}$ from Princeton Instruments, is cooled to $-50^{\circ} \mathrm{C}$ to increase the signal-to-noise ratio on the spectra. The whole set-up including the computer is mounted on a 19 -inch $(482.6 \mathrm{~mm})$ rack. While measuring, the CCD integration time is automatically adjusted to optimize the signal, typically between 0.4 and $1.3 \mathrm{~s}$. Each measurement represents a 30s average at a certain telescope angle. The acquisition is controlled automatically and the instrument does not need an operator onboard.

Several tropospheric molecules absorb light in the spectral range of our instrument and thus are potentially detectable: $\mathrm{O}_{3}, \mathrm{NO}_{2}, \mathrm{HCHO}, \mathrm{CHOCHO}, \mathrm{O}_{4}$, IO and BrO. In the following, we focus on $\mathrm{O}_{4}$ and $\mathrm{NO}_{2}$ measurements which were most clearly identified during the campaign.

\subsection{The POLARCAT-France spring campaign}

The POLARCAT-France spring campaign was part of the POLARCAT international research activity (Polar Study using Aircraft, Remote Sensing, Surface Measurements and Models, of Climate, Chemistry, Aerosols, and Transport), in the framework of the International Polar Year (IPY). Based in Kiruna, Sweden $\left(68^{\circ} \mathrm{N}, 20^{\circ} \mathrm{E}\right)$, the Safire ATR-42 aircraft performed twelve scientific flights between continental Norway and Svalbard between 30 March and 11 April 2008. Scientific objectives of the campaign included the study of pollution transport, aerosol/cloud interactions and 


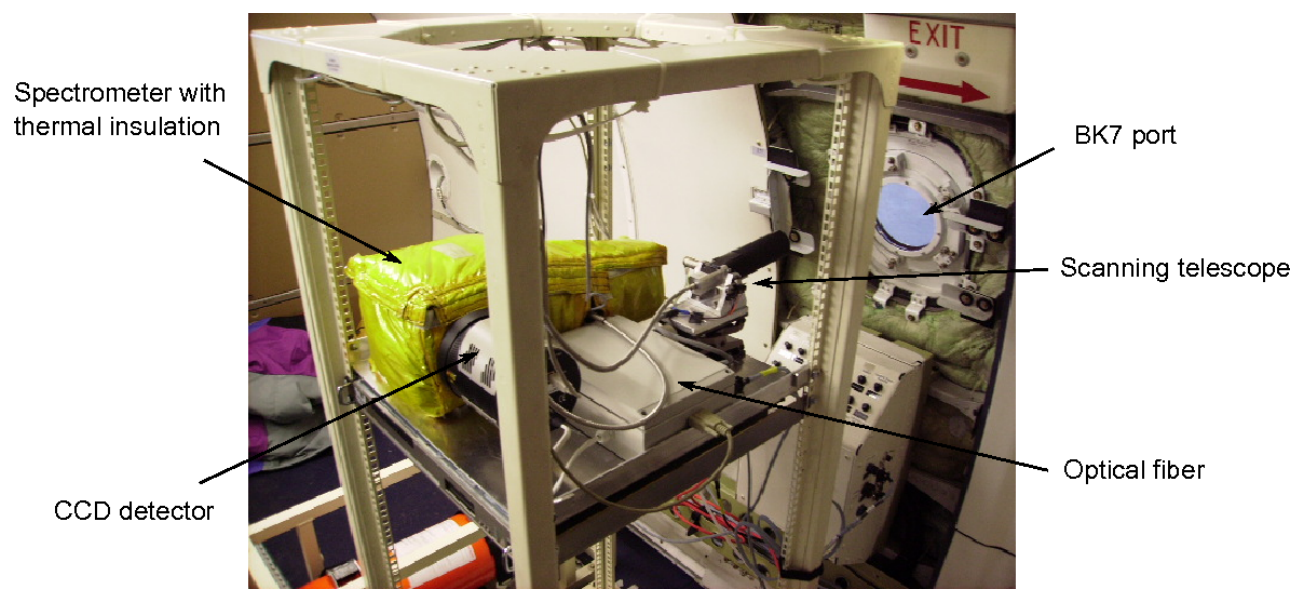

Fig. 1. The Airborne Limb Scanning Differential Optical Absorption Spectrometer (ALS-DOAS) onboard the Safire ATR-42 aircraft. A scanning telescope collects scattered sky-light at different angles near the horizon, this light being transmitted through an optical fiber to a grating spectrometer. A CCD detector is used to record the spectra. See text for technical details.

satellite validation. Various flight patterns were achieved in different weather conditions to fulfill these different research requirements. The aircraft's payload included remote sensing (e.g. Lidar, Radar) and in situ instruments (e.g. aerosol sampler, cloud particle imager). In Sect. 4, the aerosol size distributions measured by the Scanning Mobility Particle Sizer (SMPS, Villani et al., 2008) and by the Passive Cavity Aerosol Spectrometer Probe (PCASP 100-X DMT) aboard the Safire ATR-42 are used to calculate aerosol extinctions and compared with our retrievals. Together the instruments cover the size range between 0.02 and $3 \mu \mathrm{m}$. In Sect. 5 we also present ozone and $\mathrm{CO}$ profiles from the MOZART instrument (Nédélec et al., 2003, Ancellet et al., 2009) and attenuated backscatter ratio profiles at $532 \mathrm{~nm}$ and $1062 \mathrm{~nm}$ measured with the Lidar as described in de Villiers et al. (2010). The ALS-DOAS instrument recorded spectra continuously during the campaign, except during the flight as 0829 (7 April 2008) due to a computer problem. Here we focus on the data collected during two soundings on 8 (flight as0831) and 9 April 2008 (flight as0833), respectively at $71^{\circ} \mathrm{N}, 22^{\circ} \mathrm{E}$ and $70^{\circ} \mathrm{N}, 17.8^{\circ} \mathrm{E}$. Figure 2 displays these flight tracks and the position of the soundings. During the first sounding, the plane was first flying at $6 \mathrm{~km}$ then started a spiral descent (between 09:35 and 09:59 UTC), and reached the marine boundary layer where it continued with a level flight at $300 \mathrm{~m}$. The sky was then cloud-free around the plane, which simplifies the radiative transfer calculations and reduces considerably the uncertainties in the results. During the second sounding, the plane, flying at $5 \mathrm{~km}$ altitude, started its descent at 09:44 UTC and reached its lowest altitude $(250 \mathrm{~m})$ at 10:04. Some clouds were present close to the sea surface.

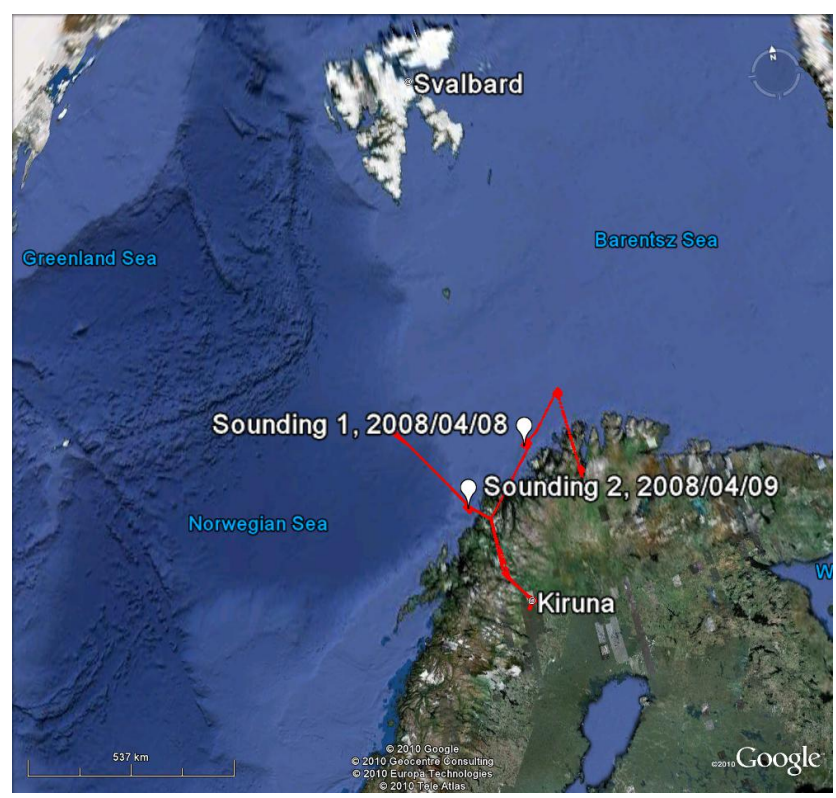

Fig. 2. Tracks of the flights as0831 (8 April 2008) and as0833 (9 April 2008) of the POLARCAT-FRANCE Spring campaign. Two soundings are studied in this work, respectively at $71^{\circ} \mathrm{N}, 22^{\circ} \mathrm{E}$ and $70^{\circ} \mathrm{N}, 17.8^{\circ} \mathrm{E}$.

\section{Spectral analysis and profiling method}

The data analysis consists of three steps: (1) quantification of $\mathrm{O}_{4}$ and $\mathrm{NO}_{2}$ molecular absorptions in the spectra, (2) retrieval of the vertical distributions of aerosol extinction and $\mathrm{NO}_{2}$ concentration from these measured absorptions and (3) error budget. 
Table 1. DOAS analysis settings.

\begin{tabular}{l|ll}
\hline & $\mathrm{O}_{4}$ & $\mathrm{NO}_{2}$ \\
\hline Fitting & $340-370$ & $415-446$ \\
window & $\mathrm{nm}$ & $\mathrm{nm}$ \\
$\mathrm{O}_{4}$ & Hermans (see text) & Ibid. \\
$\mathrm{NO}_{2}$ & Bogumil et al. (2003) & Ibid. \\
$\mathrm{O}_{3}$ & Bogumil et al. (2003) & Ibid. \\
$\mathrm{H}_{2} \mathrm{O}$ & - & Harder and Brault (1997) \\
Ring & Chance and Spurr (1997) & Ibid. \\
$\begin{array}{l}\text { Polynomial } \\
\text { order }\end{array}$ & 3 & 5 \\
\hline
\end{tabular}

The first step is achieved with the DOAS technique (Platt and Stutz, 2008) which disentangles specific absorptions from other contributions in the spectra. These absorptions do not depend only on aerosol extinction and $\mathrm{NO}_{2}$ concentration but also on other geophysical parameters and on the measurement geometries. The second step involves a modeling of the atmospheric radiative transfer to study the sensitivity of the measurements to aerosol extinction and $\mathrm{NO}_{2}$ concentration and a regularization method to solve the inverse problem of retrieving those quantities. We use the maximum a posteriori solution as described in Rodgers (2000), which also provides a rigorous error analysis.

\subsection{DOAS analysis}

Molecular absorptions such as those of $\mathrm{O}_{4}$ and $\mathrm{NO}_{2}$ are commonly retrieved in uv-visible atmospheric spectra using the DOAS technique. This method relies on the fact that their absorption cross-sections vary much more rapidly with wavelength than the scattering effects (Rayleigh and Mie). In practice, a measured spectrum $(I(\lambda))$ is divided by a reference one $\left(I_{\text {ref }}(\lambda)\right)$ to remove solar Fraunhofer structures and reduce instrumental effects. The slow variations in this ratio are filtered out with a low-order polynomial $(P(\lambda))$ and the remaining absorption structures are fitted in a leastsquare sense with high-pass filtered laboratory cross-sections $\left(\sigma_{i}^{\prime}(\lambda)\right)$. DOAS thus enables application of the Beer-Lambert law in the atmosphere, in a form that can be written as:

$\ln \frac{I(\lambda)}{I_{\mathrm{ref}}(\lambda)}=-\sum_{i} \sigma_{i}^{\prime}(\lambda) \cdot \operatorname{DSCD}_{i}+P(\lambda)$

In the above equation the index $i$ represents one particular absorber. DOAS analysis results are, for each considered absorber, in the form of differential slant column density (DSCD), i.e. the difference between the concentration integrated along the optical path corresponding to the measured spectrum and the same quantity in the reference spectrum.

Table 1 lists the DOAS analysis settings used for the retrievals of $\mathrm{O}_{4}$ and $\mathrm{NO}_{2}$ DSCDs. These settings were implemented in the QDOAS software, developed at BIRA-IASB

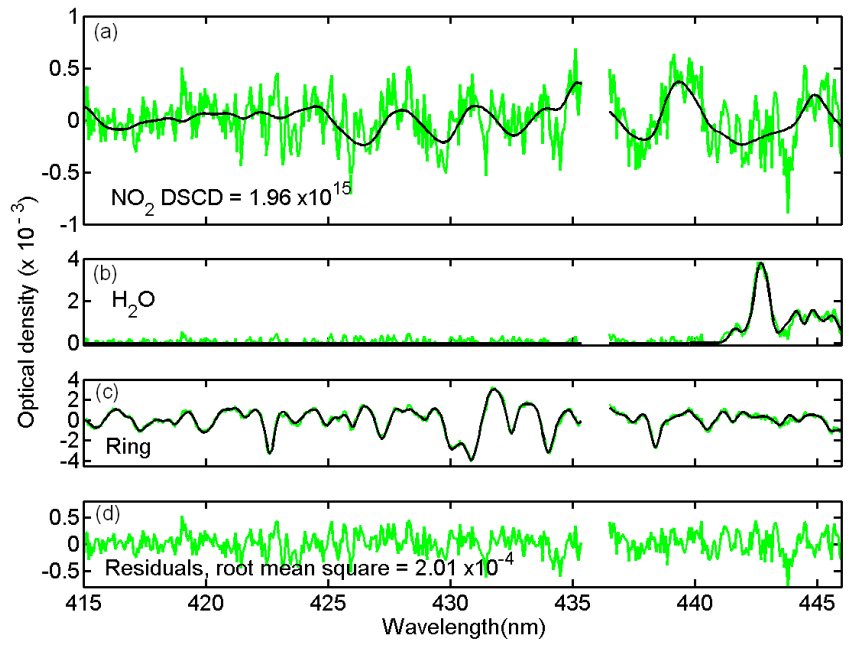

Fig. 3. Example of a DOAS fit of a spectrum recorded on 8 April 2008, when the plane was in the marine boundary layer. Black lines correspond to molecular and Ring cross-sections scaled to the detected absorptions in the measured spectrum (green lines). Note that the pixels between 435.4 and $436.5 \mathrm{~nm}$ are damaged.

(Fayt et al., 2011). The molecular cross-sections references are in the table except for $\mathrm{O}_{4}$ for which we use the Hermans version (http://www.aeronomie.be/spectrolab/o2.htm). The Ring effect (Grainger and Ring, 1962) originates from rotational Raman scattering by $\mathrm{O}_{2}$ and $\mathrm{N}_{2}$ and produces a fillingin of solar Fraunhofer lines in scattered light. We fit a Ring pseudo-absorption as described in Chance and Spurr (1997) to take it into account.

Figure 3 presents a typical $\mathrm{NO}_{2}$ DOAS result. The spectrum was recorded at 09:57 UTC when the aircraft was flying at $0.43 \mathrm{~km}$ altitude inside the marine boundary layer during the flight as0831 (8 April 2008). The solar zenith and relative azimuth angles were then respectively $64^{\circ}$ and $223^{\circ}$. The telescope angle was $-1^{\circ}$ which corresponded to a range between $-10^{\circ}$ and $+20^{\circ}$ around the horizon, due to the plane's roll variations during the 30 s of the measurement. The reference spectrum was recorded on the same flight at high altitude (see Sect. 4.1). The figure shows the $\mathrm{NO}_{2}$ fit (panel a), the water vapor optical density (panel b) which contributes significantly to the signal at the end of the analysis spectral window, the Ring effect (panel c) and the fit residuals (panel d). Note that the pixels between 435.4 and $436.5 \mathrm{~nm}$ are damaged and therefore not considered in the DOAS fit.

\subsection{Radiative transfer modeling}

The DSCDs obtained with the DOAS analysis depend on the light path, which is different for every single observation due to the telescope scanning and the variations in azimuth and altitude when the planes performs a vertical sounding. Moreover, for scattered sky-light as in our experiment, multiple 
unknown photon paths contribute to the signal simultaneously. Modeling the radiative transfer in the atmosphere enables us to define an effective light path necessary to interpret the measurements.

The radiative transfer model we use here is UVspec/DISORT (Mayer and Kylling, 2005). It is based on the discrete ordinate method and deals with multiple scattering in a pseudo-spherical approximation. Radiances at a given wavelength and absolute slant column densities (SCD) for molecules of interest can be calculated, for a geometry and a predefined atmospheric state. Considering our DOAS fitting windows, the calculations were done at 360 and $440 \mathrm{~nm}$ respectively for $\mathrm{O}_{4}$ and $\mathrm{NO}_{2}$. To calculate the true SCD from the DOAS DSCDs measurements, $\mathrm{SCD}$ in the reference spectrum ( $\left.\mathrm{SCD}_{\text {ref }}\right)$ must be estimated (cf. Sect. 4.1).

Some of the atmospheric state parameters, usually sources of uncertainties in the retrieval of a particular geophysical quantity, were measured in-situ onboard the plane, such as the temperature, pressure and ozone concentration. We use their measured profiles in our model, completed higher up in the troposphere and in the stratosphere with values extracted from the TOMSV8 climatology (McPeters et al., 2007). The latter depends on the ozone total column, estimated at 390 Dobson units in our case from the AURA AVDC values at Ny-Ålesund and Troms $\varnothing$ (http://avdc.gsfc.nasa.gov/). The $\mathrm{NO}_{2}$ profile is built from the TM4 model (Boersma et al., 2007), the stratospheric part being scaled to reproduce the stratospheric vertical column measured by the OMI instrument. The albedo of open-water can be calculated accurately assuming a Fresnel reflection (Brandt et al., 2005) which leads to an albedo value of 0.1 for $65^{\circ}$ solar zenith angle. This value depends on the refractive index of water which is almost constant between 350 and $450 \mathrm{~nm}$ so the same albedo value was used for the two wavelengths. The aerosol optical properties (extinction, absorption and asymmetry parameter) are estimated using the OPAC software package (see next section).

The observation geometry is not constant during a measurement due to the circular flight pattern and the 30s accumulation time. In particular the relative azimuth angle varies by up to $30^{\circ}$. To overcome this problem, we calculate each SCD at a single telescope angle as a weighted mean of 9 intermediary SCDs equally distributed in the 30s measurement interval. The weights correspond to the different radiances calculated in the respective intermediate SCD geometries, defined by the corresponding orientations and altitudes of the aircraft, telescope angles and solar positions.

Once the atmospheric state and the geometry are defined, the sensitivity of the measurement to a parameter $x$ can be expressed as the derivative $\frac{\partial \mathrm{SCD}}{\partial x}$. For a vertical distribution $\mathbf{x}=x_{i=1 \ldots n}$, e.g. of $\mathrm{NO}_{2}$, the weighting function is the sensitivity of a measurement to the values of the distribution in the layers $\frac{\partial \mathrm{SCD}}{\partial x_{i}}$. Weighting functions are required to retrieve vertical distributions. We calculate them by perturbations on the
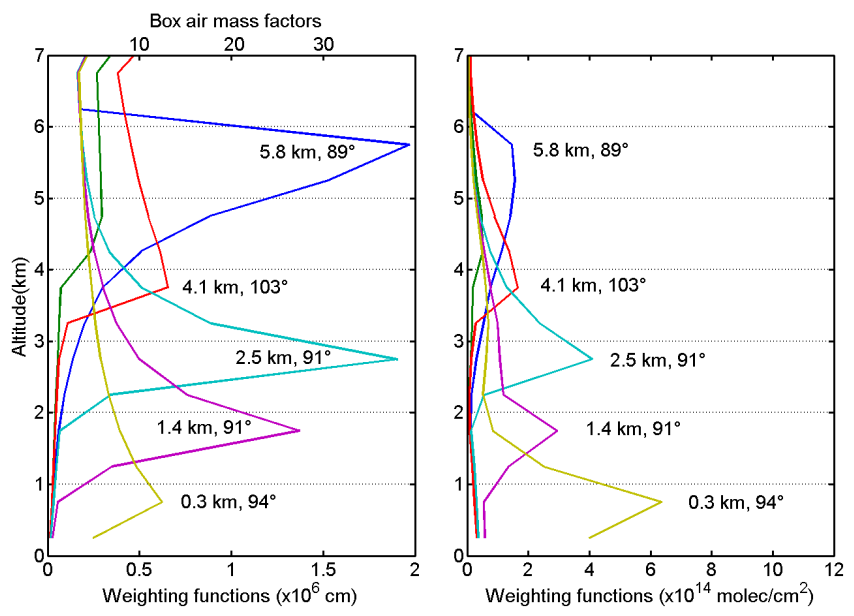

Fig. 4. Some of the weighting functions relative to the $\mathrm{NO}_{2}$ slant column measurements of the 8 April 2008 in linear (left panel) and logarithmic (right panel) scale. Beside the altitudes of observations are indicated the telescope line-of-sight angles $\left(0^{\circ}\right.$ is nadir, $90^{\circ}$ horizontal).

predefined profiles of extinction and $\mathrm{NO}_{2}$. In addition to the linear weighting functions $\left(\frac{\partial \mathrm{SCD}_{\mathrm{O}_{4}}}{\partial \mathrm{ext}_{i}}, \frac{\partial \mathrm{SCD}_{\mathrm{NO}_{2}}}{\partial\left[\mathrm{NO}_{2}\right]_{\mathrm{i}}}\right)$, we also calculate logarithmic weighting functions $\left(\frac{\partial \mathrm{SCD}_{\mathrm{O}_{4}}}{\partial \ln \operatorname{ext}_{i}}, \frac{\partial \mathrm{SCD}_{\mathrm{NO}_{2}}}{\partial \ln \left[\mathrm{NO}_{2}\right]_{i}}\right)$. This enables us to constrain the retrievals to positive values (see next section).

Figure 4 shows typical $\mathrm{NO}_{2}$ weighting functions for the sounding of the flight as0831 (8 April 2008). While the shapes are different for the linear and logarithmic approaches, both indicate a sensitivity across the whole sounding altitude range. The maximum sensitivity is achieved for viewing angles close to the horizon $\left(90^{\circ}\right)$ at the altitude of observations. This happens when the telescope angle compensates the plane's roll and is due to the enhanced light path in this layer. This indicates that the optimal geometry for profiling applications is obtained during the ascents or descents of the plane while maintaining the telescope parallel to the horizon. The maximum absolute values vary in opposite way with the observation altitude: they tend to increase for the linear case whereas they decrease for the logarithmic one. In the first case, this is due to the reduced scattering at high altitude: as aerosol and Rayleigh scattering decrease the light path increases. In the second case, this effect, still present, is dominated by the decrease of sensitivity to the logarithm for smaller concentrations, as most of the $\mathrm{NO}_{2}$ in the predefined profile is assumed to be in the boundary layer. Indeed, for small $\left[\mathrm{NO}_{2}\right]$ values, $\partial \ln \left[\mathrm{NO}_{2}\right]$ gets large and reduces thus the derivative $\frac{\partial \mathrm{SCD}_{2}}{\partial \ln \left[\mathrm{NO}_{2}\right]_{i}}$.

Dividing the linear weighting functions by the layers' thickness defines the box air mass factors (box AMF, Wagner et al., 2007). The box AMF scale is also displayed on Fig. 4 and can be compared with the same quantity calculated for 
nadir looking satellites (e.g. by Zhou et al., 2009, Fig. 7) and ground-based MAX-DOAS instruments (e.g. by Wittrock et al., 2004, Fig. 4). In the OMI case, Zhou et al. indicates a box air mass ranging from unity near the ground to two in the high troposphere. Ground-based MAX-DOAS measurements are most sensitive close to the ground, corresponding to quasi horizontal pointing, when the light path enhancement is maximum. The box AMF, around 20, is then comparable to airborne limb measurements. But this sensitivity decreases rapidly with altitude contrary to our airborne set-up which enables to look the horizon from any altitude reachable by the plane. As a result, the airborne approach is particularly well suited for the study of the free troposphere

\subsection{Retrieval of the geophysical quantities with a maximum a posteriori evaluation}

The weighting functions express the sensitivity of a measurement to a vertical distribution $\mathbf{x}$, or more accurately their respective variations. For a set of measurements $\mathbf{y} y_{j=1 \ldots m}$, defining the weighting functions matrix $\mathbf{K}$ as $\frac{\partial \mathrm{SCD}_{j}}{\partial x_{i}}$ enables to write, if $\mathbf{x}$ is close to the linearization point $\mathbf{x}_{\mathbf{0}}$ :

$\mathbf{y}-\mathbf{y}_{\mathbf{0}}=\mathbf{K}\left(\mathbf{x}-\mathbf{x}_{\mathbf{0}}\right)+\epsilon$

where $\mathbf{y}_{\mathbf{0}}$ represents a measurement series at the linearization point $\mathbf{x}_{\mathbf{0}}$, which can be calculated with the radiative transfer model.

Due to the error $\epsilon$, which represents instrument noise and model uncertainties, the solution $\hat{\mathbf{x}}$ is a statistical estimate of the true state. The problem is generally ill-posed and some regularization is required to retrieve $\hat{\mathbf{x}}$. We use the maximum a posteriori solution as presented in Rodgers (2000), often referred as "optimal estimation". It requires a priori knowledge of the quantity to retrieve and assumes Gaussian statistics for this a priori and the error. The solution with maximum probability after the measurements (a posteriori), due to the nonlinearity of the problem, must be reached by iterations, in our case with the Gauss-Newton algorithm:

$\mathbf{x}_{\mathbf{i}+\mathbf{1}}=\mathbf{x}_{\mathbf{i}}+$

$\left(\mathbf{S}_{\mathbf{a}}^{-1}+\mathbf{K}_{\mathbf{i}}^{\mathbf{T}} \mathbf{S}_{\epsilon}^{-1} \mathbf{K}_{\mathbf{i}}\right)^{-1}\left[\mathbf{K}_{\mathbf{i}}^{\mathbf{T}} \mathbf{S}_{\epsilon}^{-1}\left(\mathbf{y}-\mathbf{F}\left(\mathbf{x}_{\mathbf{i}}\right)\right)-\mathbf{S}_{\mathbf{a}}^{-1}\left(\mathbf{x}_{\mathbf{i}}-\mathbf{x}_{\mathbf{a}}\right)\right]$

where $\mathbf{S}_{\mathbf{a}}$ and $\mathbf{S}_{\epsilon}$ are respectively the a priori and error covariance matrix, and $\mathbf{K}_{\mathbf{i}}$ the weighting functions matrix calculated with the vertical distribution $\mathbf{x}_{\mathbf{i}}$.

After convergence, the solution is a weighted mean of the a priori knowledge and the information coming from the measurement. The averaging kernels matrix $\mathbf{A}$ measures this weight, its trace being the number of independent pieces of information retrieved, namely the degree of freedom for the signal (DOFS):

$\mathbf{A}=\left(\mathbf{K}_{\mathbf{i}}^{\mathrm{T}} \mathbf{S}_{\epsilon}^{-1} \mathbf{K}_{\mathbf{i}}+\mathbf{S}_{\mathbf{a}}^{-1}\right)^{-1} \mathbf{K}_{\mathbf{i}}^{\mathrm{T}} \mathbf{S}_{\epsilon}^{-1} \mathbf{K}_{\mathbf{i}}$

The averaging kernels matrix also contains information about the vertical resolution of the retrieval: for a given level, it is estimated from the full width at half maximum (FWHM) of the main peak of the corresponding averaging kernel.

To save computing time, we do not recalculate the weighting function matrices $\mathbf{K}_{\mathbf{i}}$ after each iteration, as suggested in Rodgers (2000). With this approximation, which seems reasonable since the real state is close to the linearization point, the retrieval takes around one hour to converge. Moreover $\mathbf{S}_{\mathbf{a}}$ is used here as a tuning parameter. In practice, $\mathbf{S}_{\mathbf{a}}$ is a diagonal matrix with coefficients $\mathbf{S}_{\mathbf{a}}(i, i)$ constructed respectively as $\beta x_{a}^{2}(i, i)$ or $\beta \ln x_{a}{ }^{2}(i, i)$ in the linear or logarithmic retrieval, and $\beta$ is adjusted to optimize the DOFS while preventing non-physical values and oscillations in the retrieved profiles.

For both extinction and $\mathrm{NO}_{2}$ retrievals, vertical distributions corresponding to a priori, linearization point and starting point of the Gauss-Newton iterations are the same. Both soundings are retrieved independently. For the first sounding (8 April 2008), the chosen altitude grid extends from 0 up to $8 \mathrm{~km}$ in steps of $0.5 \mathrm{~km}$ each, except for the lowest step which is $1 \mathrm{~km}$ thick. For the second sounding (9 April 2008), clouds prevent modelling of the radiative transfer in the lower part of the atmosphere and, therefore, the grid starts at $3 \mathrm{~km}$ and the layers are $1 \mathrm{~km}$ thick up to $8 \mathrm{~km}$.

The a priori on aerosol extinction profiles are constructed with the software package OPAC (Optical properties of Aerosol and Clouds, Hess et al., 1998). OPAC assumes ten types of spherical particles that can be mixed to reproduce typical aerosol conditions and provides their optical properties in the solar and terrestrial spectral range as a function of relative humidity. Conveniently, one of these predefined mixtures corresponds to the Arctic spring, and the relative humidity was measured in situ during the flight. Figure 5 shows an a priori extinction profile built from the OPAC output at $350 \mathrm{~nm}$, the closest wavelength in OPAC to the $\mathrm{O}_{4}$ $360 \mathrm{~nm}$ absorption band, together with measured relative humidity.

For the $\mathrm{NO}_{2}$ retrieval, the extinction profile at $360 \mathrm{~nm}$ retrieved from $\mathrm{O}_{4}$ DSCDs is corrected to take into account the scattering reduction in the visible with OPAC Angstrom coefficients. The a priori $\mathrm{NO}_{2}$ vertical distribution is extracted from the corresponding TM4 vertical distributions available with the DOMINO (Dutch OMI NO 2 ) product (http://www. temis.nl/airpollution/no2col/no2regioomi_v2.php).

The assumption of Gaussian statistics, needed to establish Eq. (3) is realistic for the instrument noise but less obvious for the quantity to retrieve. For positive geophysical quantities with large variability around a small mean, a significant part of the probability density lies in the negative range which is unphysical. Retrieving the logarithm of the quantity, i.e. assuming a lognormal probability distribution, can overcome the problem. It implies calculating logarithmic weighting functions, as described in the previous section. This has been done already, e.g. for water vapor (Schneider et al., 2006), and CO (Deeter et al., 2007). For these two species, the authors further indicate that in situ measured statistics are 


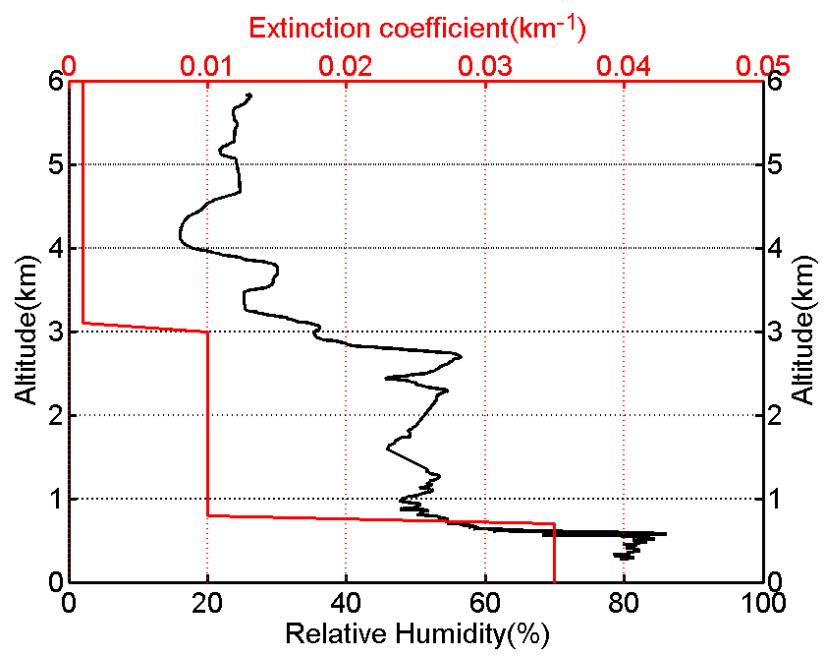

Fig. 5. Construction of the a priori aerosol extinction coefficient profile (red) from the measured relative humidity (black). The extinction values are derived for $350 \mathrm{~nm}$ from the software package OPAC, using the Arctic Spring predefined aerosol type.

closer to lognormal distributions. We compare the results of both methods in Sect. 4.

\subsection{Error analysis}

The uncertainties in the retrieval originate from three sources: the instrument noise, the uncertainties in the model parameters which are not retrieved (e.g. albedo) and the finite vertical resolution of the retrieval. The error from the model itself is neglected, which seems reasonable from previous intercomparison exercises (Hendrick et al., 2006).

The two first sources limit the accuracy in relating a profile $\mathbf{x}$ to a set of measurements $\mathbf{y}$ and correspond to the measurement error $\epsilon$ in Eq. (2). The associated error covariance matrix is calculated from the noise covariance $\left(\mathbf{S}_{\mathbf{N}}\right)$ and the model parameters covariance $\left(\mathbf{S}_{\mathbf{b}}\right)$ according to:

$\mathbf{S}_{\epsilon}=\mathbf{S}_{\mathbf{N}}+\mathbf{K}_{\mathbf{b}} \mathbf{S}_{\mathbf{b}} \mathbf{K}_{\mathbf{b}}^{\mathbf{T}}$

where $\mathbf{K}_{\mathbf{b}}$ is the matrix of sensitivities to the model parameters, constructed by perturbations on these parameters.

The noise covariance $\mathbf{S}_{\mathbf{N}}$ is built with the square of the error in the slant columns, which is an output of the DOAS analysis depending on the fit residuals, the off-diagonal elements are neglected.

Retrieving $\mathrm{O}_{4}$ profiles in a similar experiment, PradosRoman et al. (2011) identified the albedo and the asymmetry parameter as major sources of model parameter errors. We introduce uncertainties on these parameters with respective standard deviations of 0.02 and 0.01 . To take into account the $\mathrm{O}_{4}$ cross-section uncertainties (see Sect. 4.1), another error source was introduced corresponding to $2 \%$ of the measured DSCD. For the $\mathrm{NO}_{2}$ retrieval, we consider uncertainties with respect to the albedo $(\sigma=0.02)$ and on the aerosol extinction, with standard deviations estimated from our extinction retrieval.

The measurement error, with its covariance $\mathbf{S}_{\epsilon}$ is propagated in the retrieval with the gain matrix $\mathbf{G}$ defined as $\left(\mathbf{K}^{\mathbf{T}} \mathbf{S}_{\epsilon}^{-1} \mathbf{K}+\mathbf{S}_{\mathbf{a}}^{-\mathbf{1}}\right)^{-\mathbf{1}} \mathbf{K}^{\mathbf{T}} \mathbf{S}_{\epsilon}^{-\mathbf{1}}$, representing the relationship between the retrieval and the signal. The corresponding retrieval error covariance is thus expressed as:

$\mathbf{S}_{\mathbf{R}}=\mathbf{G S}_{\epsilon} \mathbf{G}^{\mathbf{T}}$

The retrieval is a smoothed version of the true profile. This finite vertical resolution is the third error source and is calculated as:

$\mathbf{S}_{S}=(\mathbf{A}-\mathbf{I}) \mathbf{S}_{\mathrm{var}}(\mathbf{A}-\mathbf{I})$

where $\mathbf{S}_{\mathrm{var}}$ is the natural variability covariance and $\mathbf{I}$ the identity matrix. Natural variability is often difficult to quantify. For the extinction, we estimate it from AOD measurements between 1995 and 1999 at Ny-Ålesund (Herber et al., 2002). This study presents statistics for measurements at $532 \mathrm{~nm}$ for different seasons and conditions. The background (no Arctic Haze) spring value is $0.067 \pm 0.017$. Considering this, the variability covariance matrix is built assuming standard deviations of 0.005 in all the layers with relative humidity larger than $50 \%$, no correlation is considered between the layers. For $\mathrm{NO}_{2}$, natural variability in the free troposphere is derived from the TOPSE aircraft campaign. Stroud et al. (2003) give statistics for the $\mathrm{NO}_{\mathrm{x}}$ measurement during the campaign: a mean and standard deviation of $17 \pm 13$ pptv. Interestingly the median is also calculated and its value, $15 \mathrm{pptv}$, is smaller than the mean, which is typical of a lognormal distribution. We use the standard deviation of these $\mathrm{NO}_{\mathrm{x}}$ measurements. Again, no off-diagonal elements are added to the variability covariance matrix. Figure 6 displays the different error sources and their propagation in the aerosol extinction retrieval on 8 April 2008. The error profiles for each parameter represent the square root of the diagonal elements of its covariance matrix. It is noteworthy that the main error source on the measurements, the albedo, is insignificant after the retrieval. The total uncertainty appears dominated by the smoothing error.

\section{Results for the soundings on 8 and 9 April 2008}

In this section, we present the $\mathrm{O}_{4}$ and $\mathrm{NO}_{2}$ DSCD measured during the flights as0831 (8 April 2008) and as0833 (9 April 2008) and the corresponding retrieved aerosol extinction and $\mathrm{NO}_{2}$ concentration profiles, for which we compare the linear and logarithmic approach. Between these two steps, we make sure the measurements are qualitatively reproduced by the radiative transfer model and use the latter to infer in particular the residual columns in the reference spectrum and a detection limit for $\mathrm{NO}_{2}$. 

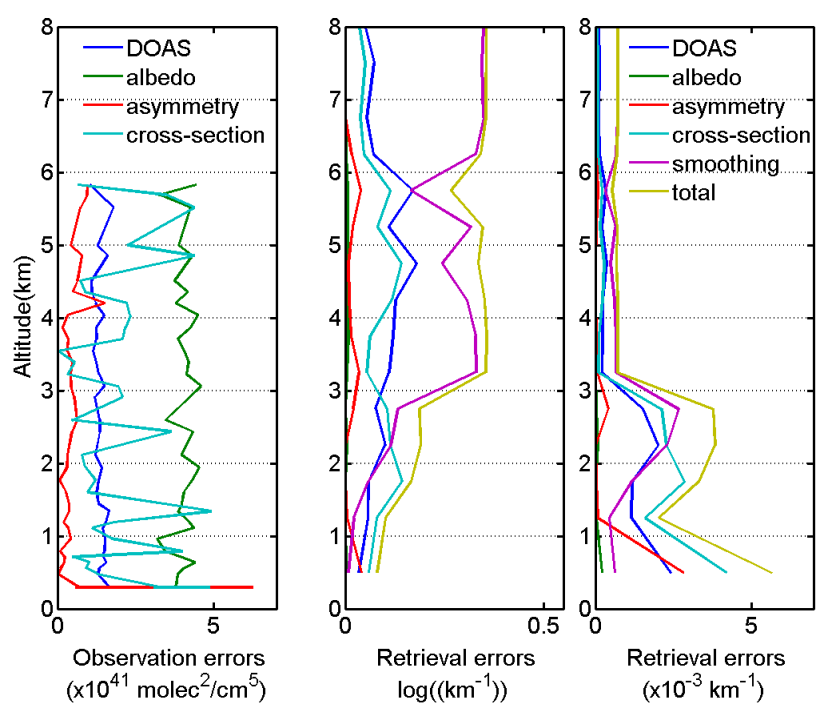

Fig. 6. Error contributions for the extinction profile of the 8 April 2008 retrieved in logarithmic scale, estimated from the diagonal elements of the error covariance matrices.

\subsection{Residual slant columns and $\mathrm{O}_{4} \mathrm{DSCD}$ scaling factor}

As described in Sect. 3.1, our DSCD measurements are relative to the slant column in a reference spectrum. Determination of this reference column is thus necessary for any further quantitative discussion on geophysical quantities. $\mathrm{O}_{4}$ and $\mathrm{NO}_{2}$ DSCDs presented in the following are relative to their respective columns in the same spectrum, selected at the top of the as 0831 sounding, near $6 \mathrm{~km}$ altitude. The telescope angle was then $0^{\circ}$. For both species the reference slant column is estimated comparing high altitude DSCD measurements with calculated SCDs. We make the assumption that the geophysical quantities to be retrieved do not affect significantly the slant column calculation at high altitude, which we believe is a reasonable hypothesis based on sensitivity tests using the radiative transfer model. $\mathrm{O}_{4}$ DSCD measurements are commonly corrected with ad hoc scaling factors to retrieve extinction. During an intercomparison exercise involving four MAX-DOAS instruments, Zieger et al. (2010) reported scaling factors from 0.75 to 0.83 . Spectra obtained at high altitudes give an opportunity to estimate accurately such a scaling factor. Indeed, the $\mathrm{O}_{4}$ vertical distribution depends only on the air density, which can be calculated from pressure and temperature measured onboard the plane. Moreover, aerosol scattering, the major uncertainty source in $\mathrm{O}_{4} \mathrm{SCD}$ calculations, can be neglected above $6 \mathrm{~km}$ and this is confirmed by comparing measurements and simulations.

To quantify the $\mathrm{O}_{4}$ residual slant column in the reference spectrum $\left(\mathrm{SCD}_{\text {ref }}\right)$ and the DSCD correction factor $(\alpha)$, we apply a linear regression between measured DSCD and cal-

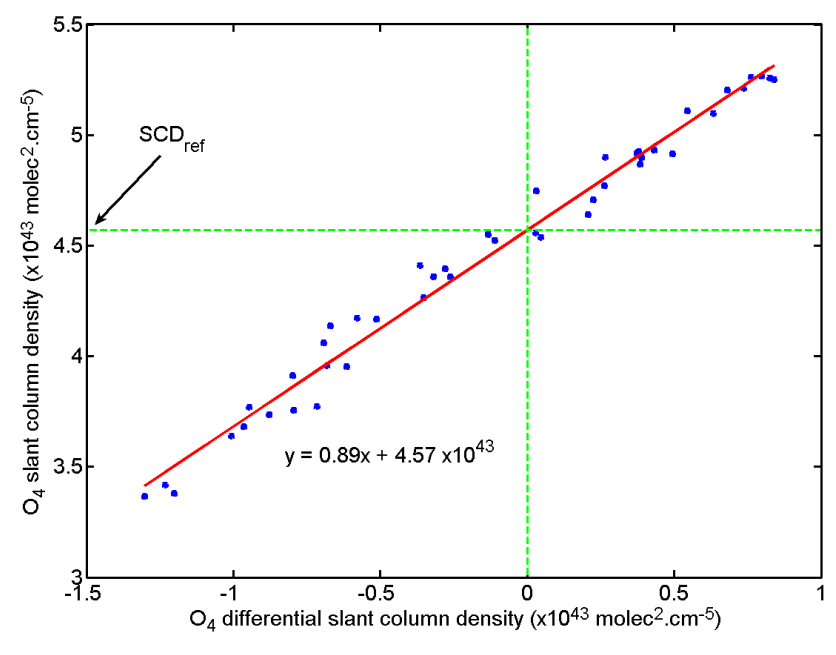

Fig. 7. Determination of the residual column density and of the $\mathrm{O}_{4}$ DSCD scaling factor. DSCD measurements at high altitude, where aerosols scattering can be neglected, are plotted versus simulated absolute SCD. The linear regression fits simultaneously the residual slant column density in the reference spectrum (the intercept, $\mathrm{SCD}_{\text {ref }}$ ) and the DSCD correcting factor (the slope).

culated SCD in the same geometries:

$\mathrm{SCD}=\alpha \cdot \mathrm{DSCD}+\mathrm{SCD}_{\mathrm{ref}}$

Figure 7 shows the fit results for two $\mathrm{O}_{4}$ DSCD series measured when the aircraft was flying above $5.5 \mathrm{~km}$. The modeled atmosphere neglects aerosol scattering but uses the in situ measurements (pressure, temperature, ozone) during the sounding. The $\mathrm{O}_{4}$ vertical distribution is calculated from the observed pressure and temperature. This leads to a scaling factor $\alpha$ of 0.89 . DSCD measurements used to retrieve the aerosol extinction coefficient were therefore scaled by this value, which is higher than the values reported by Zieger et al., but closer to the direct-sun measurements of Spinei (see http://www.knmi.nl/omi/documents/presentations/2010/ ostm15/OSTM15_AIS_Spinei_O2-O2_Cross_Sections.pdf).

For $\mathrm{NO}_{2}$ measurements, we use the same high-altitude series to estimate a reference $\mathrm{SCD}$, without fitting a correction factor on the cross-section. This leads to a $\mathrm{NO}_{2}$ reference column of $7.81 \times 10^{15} \mathrm{molec} \mathrm{cm}^{-2}$. Aerosol optical effects are also neglected and the $\mathrm{NO}_{2}$ profile used is taken from the TM4 model (see Sect. 3.2).

\subsection{Measured versus simulated slant columns}

In Fig. 8, $\mathrm{O}_{4}$ and $\mathrm{NO}_{2}$ measured DSCDs are compared with simulations for the spectra recorded between 09:16 and 10:01 UTC during the as0831 flight. The upper panel shows the aircraft altitude and the telescope line-of-sight angle. During the period considered, the aircraft was flying at high altitude $(6 \mathrm{~km})$ before descending to the marine boundary 

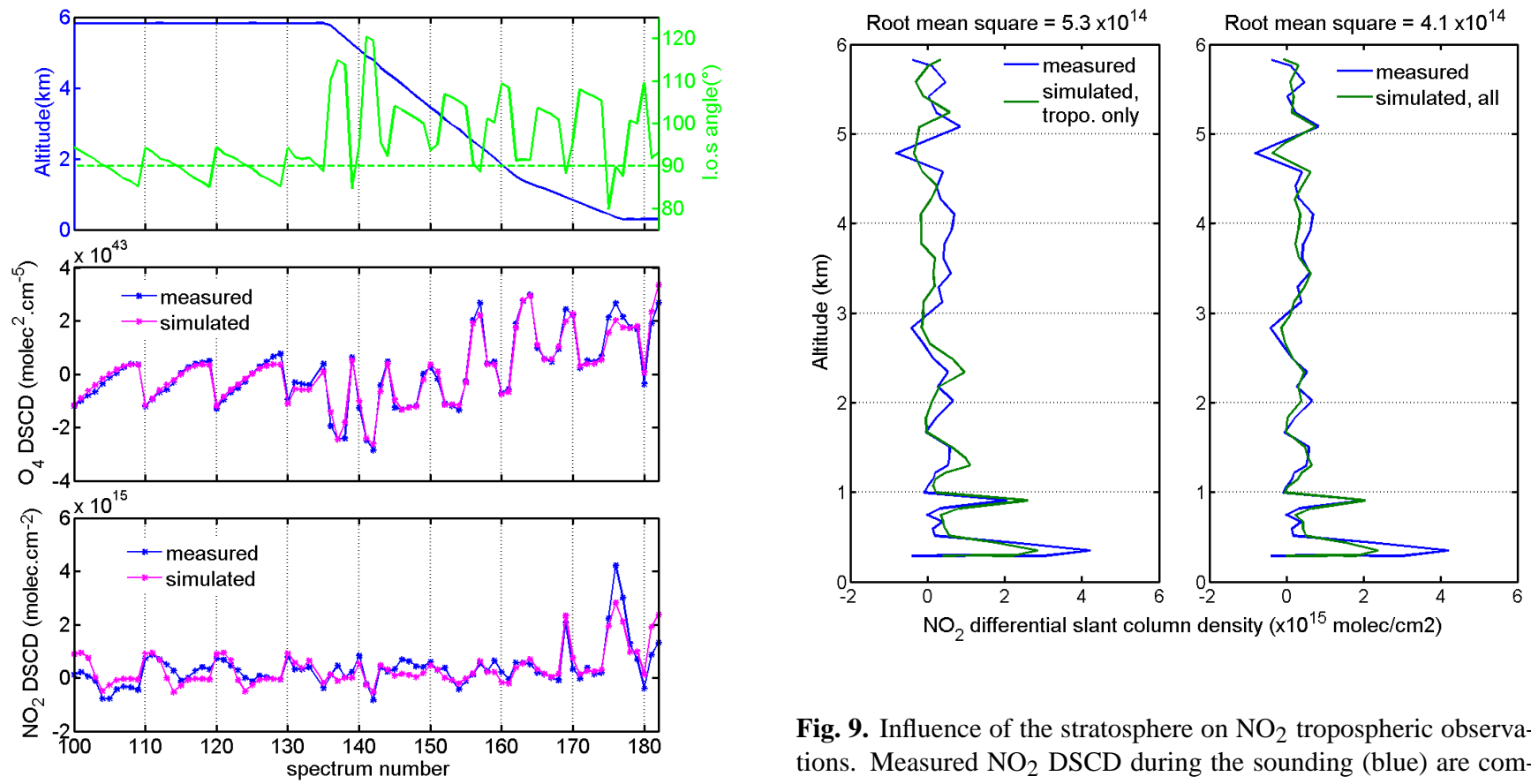

Fig. 8. DSCD measurements during the as0831 flight (8 April 2008). The upper panel shows the plane altitude (blue) and the telescope line-of-sight angle (green, $0^{\circ}$ is nadir, $90^{\circ}$ horizontal). On the middle and bottom panels, measured DSCD, respectively of $\mathrm{O}_{4}$ and $\mathrm{NO}_{2}$, are compared with simulations. Oscillations on the DSCD series are caused by the telescope scanning. Discrepancies between measured and simulated DSCD are larger in the boundary layer, where true aerosol extinction and $\mathrm{NO}_{2}$ concentration are different from the model.

layer and continuing with a level flight at $300 \mathrm{~m}$. The two lowest panels display the measured and simulated $\mathrm{O}_{4}$ and $\mathrm{NO}_{2}$ DSCD series. The telescope kept scanning during the whole period, which explains the variations in the DSCDs. These oscillations are qualitatively reproduced by the simulations, which indicates the radiative transfer in the model atmosphere approximates the measurements correctly. The $\mathrm{O}_{4}$ slant column series are closer to the simulations than the $\mathrm{NO}_{2}$, especially at high altitude, due to the weak aerosol extinction there and the known vertical distribution of $\mathrm{O}_{4}$ The oscillations are anticorrelated for the two species during the high altitude part. This is due to the fact that the $\mathrm{NO}_{2}$ signal at that altitude is dominated by the stratospheric contribution (see Sect. 4.3), and thus maximum when the telescope points upward, while the $\mathrm{O}_{4}$ concentration is largest at the ground, and so DSCD is highest when the telescope looks downward. The altitude dependence is also different for the two species. The $\mathrm{O}_{4}$ DSCD, beside the oscillations, systematically increases during the descent, which is expected from the increase of air density. In the boundary layer where the aerosol extinction limits the optical path, the DSCD decreases again.

Fig. 9. Influence of the stratosphere on $\mathrm{NO}_{2}$ tropospheric observations. Measured $\mathrm{NO}_{2}$ DSCD during the sounding (blue) are compared with simulations (green) neglecting the stratosphere (left) or not (right). The latter agrees better with the observations.

In contrast, the $\mathrm{NO}_{2}$ is stable during the descent but increases only in the boundary layer, indicating a very low $\mathrm{NO}_{2}$ concentration in the free troposphere and higher values close to the sea surface.

Deviations between measured and simulated DSCDs indicate differences between the true state of the atmosphere and the radiative transfer parameters used. This is visible at the end of the two DSCD series, corresponding to the boundary layer. In this region, aerosol extinction is no longer negligible and the $\mathrm{NO}_{2}$ concentration is higher than the one in the model atmosphere.

\section{3 $\mathrm{NO}_{2}$ : Influence of the stratosphere and detection limit}

For $\mathrm{NO}_{2}$, the $\mathrm{SCD}$ simulations reveal a substantial influence of stratospheric $\mathrm{NO}_{2}$ overhead although our measurements were performed in the troposphere. This effect can be clearly identified in Fig. 9, which compares measured $\mathrm{NO}_{2}$ DSCDs during the sounding and simulations with and without taking into account the stratospheric part. The effect is particularly visible at higher altitudes where discrepancies between the measurements and simulations without the stratospheric part are larger than discrepancies when taking into account the stratosphere. Since the $\mathrm{NO}_{2}$ concentration is low in the free troposphere, the signal originates mostly from the stratosphere and the boundary layer, where a $\mathrm{NO}_{2}$ layer is detected (see previous section). The stratospheric influence is largest when the telescope points upward, towards the stratosphere, whereas the opposite is valid for the boundary layer. 

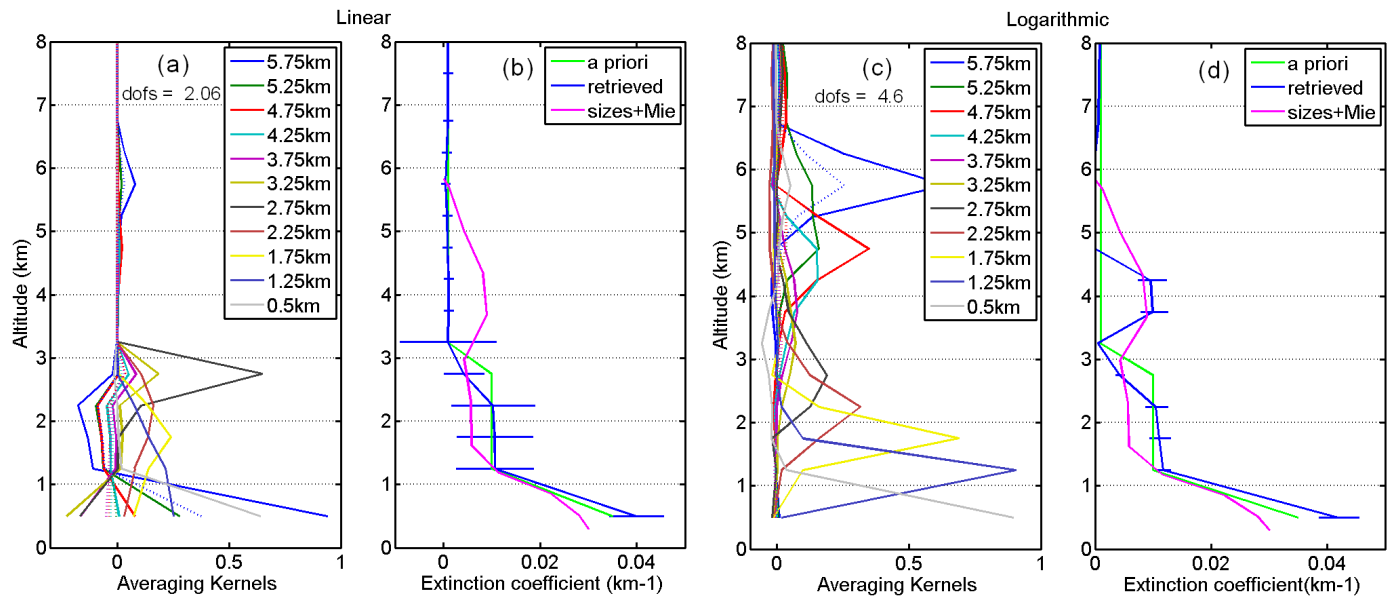

Fig. 10. Comparison of the aerosol extinction profile retrieval using linear (left) and logarithmic (right) weighting functions for the sounding of the as0831 flight (8 April 2008). For the same a priori, the logarithmic retrieval agrees better with an extinction profile calculated from in situ size distribution. Averaging kernels indicate also a higher sensitivity of the retrieval to the true state in the logarithmic case.

To constrain the stratospheric $\mathrm{NO}_{2}$ content in our simulations, we have used measurements of stratospheric $\mathrm{NO}_{2}$ columns obtained from the OMI satellite instrument, which was flying above the sounding area, precisely at 09:42 on the orbit 19850. Assimilated vertical stratospheric column $\left(2.91 \times 10^{15} \mathrm{molec} \mathrm{cm}^{-2}\right)$ from the DOMINO data product (see Sect. 3.3) have been used to scale to the TM4 vertical distribution in the stratosphere.

We estimate the minimum detectable DSCD as corresponding to an optical density of two times the DOAS fit residual root mean square deviation (RMSD). Converting this minimum DSCD to a vertical column density requires knowledge of the enhancement factor between the VCD and the DSCD, namely the air mass factor (AMF), which can be derived from simulations. The detection limit is thus $\frac{2 \mathrm{RMSD}}{\mathrm{AMF} \sigma}$ where $\sigma$ is the $\mathrm{NO}_{2}$ cross-section value. With a RMSD of around $2.1 \times 10^{-4}$ (Fig. 3) and an AMF in the boundary layer of around 10 , the minimum detectable vertical column is $7.3 \times 10^{13}$ molec $\mathrm{cm}^{-2}$. Assuming a homogeneous layer $1 \mathrm{~km}$ thick, this corresponds to a concentration of $6.6 \times 10^{8}$ molec $\mathrm{cm}^{-3}$ and a volume mixing ratio of 27 pptv. Taking the NO/NO${ }_{2}$ ratio of 0.5 given by Ridley et al. (2000) in similar conditions, this leads to a total $\mathrm{NO}_{\mathrm{x}}$ mixing ratio of $40 \mathrm{pptv}$. These detection limits are below the 50 pptv achieved with commercial airborne chemiluminescent analyzers (Ancellet et al., 2009), but above the $2 \mathrm{pptv}$ mentionned by Ridley et al. (2000) for a custom-made instrument using also the chemiluminescence technique.

\subsection{Retrievals of aerosol extinction coefficient and $\mathrm{NO}_{2}$ concentration}

Preliminary retrievals demonstrated the difficulty to reproduce quantitatively the measurements corresponding to the telescope pointing slantwise downward when the aircraft is at low altitude. A similar problem has been mentioned for DOAS ground-based measurements in the same region (Wittrock et al., 2004). Increasing the albedo improves the situation for these points but deteriorates it for the others. Wittrock et al. suggested that the presence of thin clouds might explain the problem. Such clouds were not noticed during this part of the flight so the problem could arise from another cause, e.g. a small BRDF effect on the albedo. The measurements below the horizon were not considered for the retrievals.

Figure 10 shows the retrievals of the vertical distribution of aerosol extinction coefficient for the sounding at $71^{\circ} \mathrm{N}, 22^{\circ} \mathrm{E}$ on 8 April 2008. The panels a and $\mathrm{b}$ correspond to the linear retrieval, i.e., assuming Gaussian statistics on the a priori, the panels $\mathrm{c}$ and $\mathrm{d}$ to the logarithmic retrieval and the lognormal a priori (see Sect. 3.3). Averaging kernels (panels a and c) are different for the two methods. They do not represent the same quantity in linear and logarithmic scale but indicate that the logarithmic retrieval is more strongly constrained by the measurements than the linear one, the DOFS being respectively 4.6 and 2.06. For the linear case, the averaging kernels get very close to zero above $3 \mathrm{~km}$ altitude, where the a priori extinction is 0.001 . The retrieved profiles are similar below $3 \mathrm{~km}$ altitude, with an extinction in the boundary layer of $0.04 \pm 0.005 \mathrm{~km}^{-1}$. Above $3 \mathrm{~km}$ altitude the linear retrieval, due to the averaging kernels, remains close to the a priori profile, whereas the logarithmic retrieval exhibits a layer with enhanced extinction $\left(0.01 \pm 0.003 \mathrm{~km}^{-1}\right)$ around $4 \mathrm{~km}$ altitude.

For the linear case, the loss of sensitivity to the measurements above $3 \mathrm{~km}$ is explained by the low a priori extinction in these layers. As mentioned in Sect. 3.3, the a priori covariance matrix $\left(\mathbf{S}_{\mathbf{a}}\right)$ we use is diagonal, each element being 

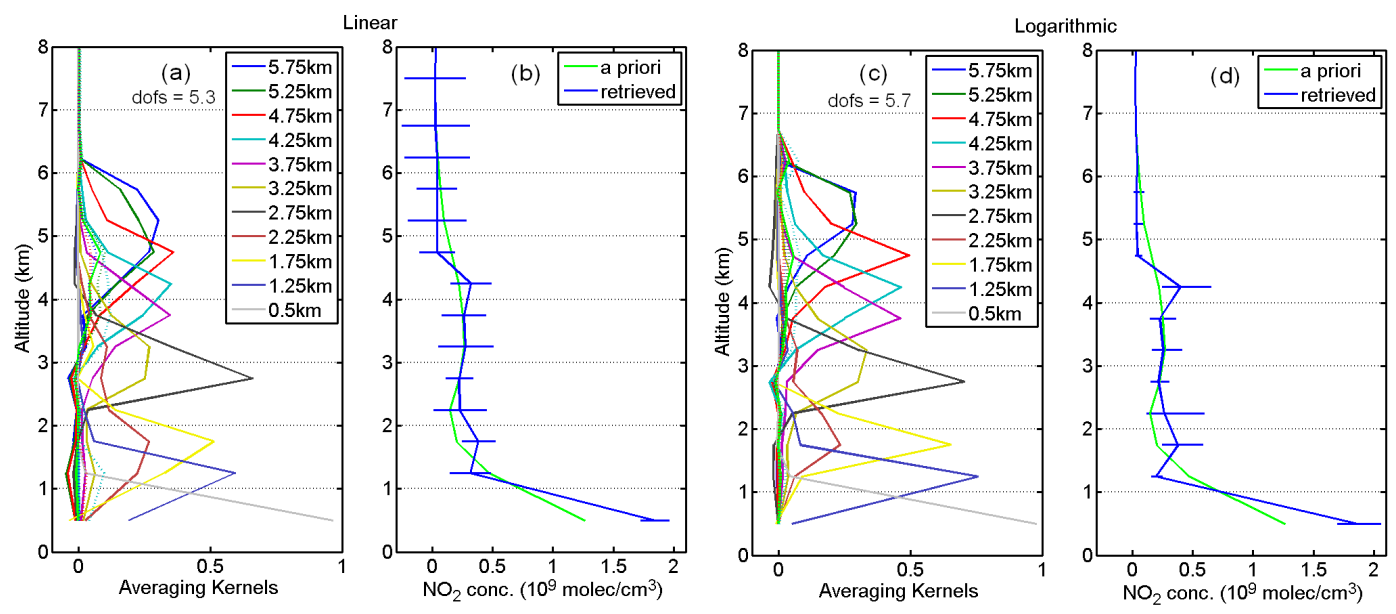

Fig. 11. Comparison of the $\mathrm{NO}_{2}$ profile retrieval using linear (left) and logarithmic (right) weighting functions for the sounding of the as 0831 flight ( 8 April 2008). The two panels show the respective averaging kernels and retrieved profiles. The results are very close, contrary to the aerosol extinction retrieval.
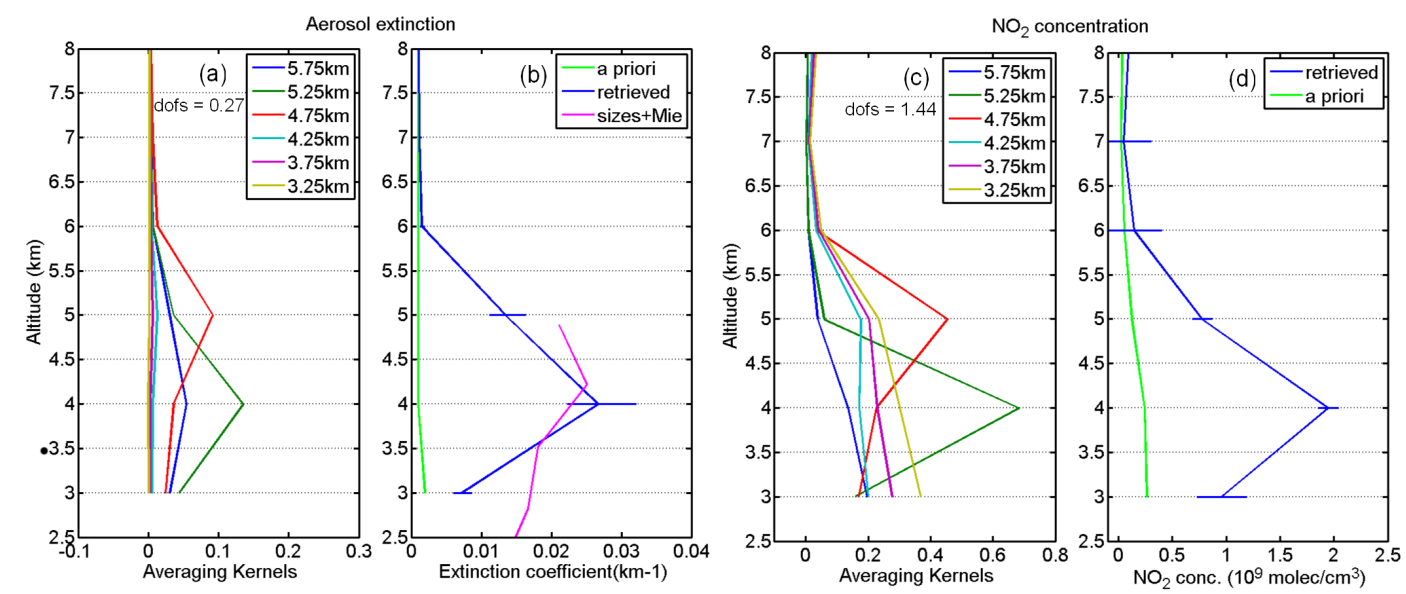

Fig. 12. Retrieved extinction and $\mathrm{NO}_{2}$ profiles for the sounding of the as 0833 flight ( 9 April 2008). Under $3 \mathrm{~km}$ high, the radiative transfer is too strongly affected by clouds to enable quantitative retrievals. Around $4 \mathrm{~km}$ high, an enhanced layer is measured for both extinction and $\mathrm{NO}_{2}$.

the variance of the aerosol extinction in the considered layer. Tuning these variances to optimize the retrieval is a trade-off: large variances lead to small constraints of the a priori compared to the measurements and thus higher DOFS. On the other hand large variances imply consideration of negative values of the probability density function as non-negligible if their square roots (the standard deviation) gets close to the mean, i.e. the apriori extinction in $\mathbf{x}_{\mathbf{a}}$. This is the case for small a priori extinction values, i.e. the ones above $3 \mathrm{~km}$ altitude. Negative aerosol extinction values are non-physical and not supported by our model. It was thus necessary when building the $\mathbf{S}_{\mathbf{a}}$ matrix to set variances small enough to avoid negative values, especially above $3 \mathrm{~km}$ altitude, reducing the sensitivity in these layers.
We show in the same figure an extinction profile calculated from the measured aerosol size distribution (see Sect. 2.2) using a Mie scattering model (Mätzler, 2002; Bond et al., 2006). We assume in the calculation a constant complex refractive index of $1.5+0.01 i$, a value taken from Tomasi et al. (2007). One of the aerosol samplers, the PCASP which measures the aerosol size distribution between 0.1 and $3 \mu \mathrm{m}$, could not be completely calibrated during the campaign. The missing calibration mainly affects aerosol extinction calculated for the marine boundary layer, where large sea-salt aerosols may be present. Nevertheless, the Mie calculation provides information about the shape of the true profile. The enhanced extinction layer at $4 \mathrm{~km}$ altitude in the Mie calculated profile is obtained only with the logarithmic retrieval. 

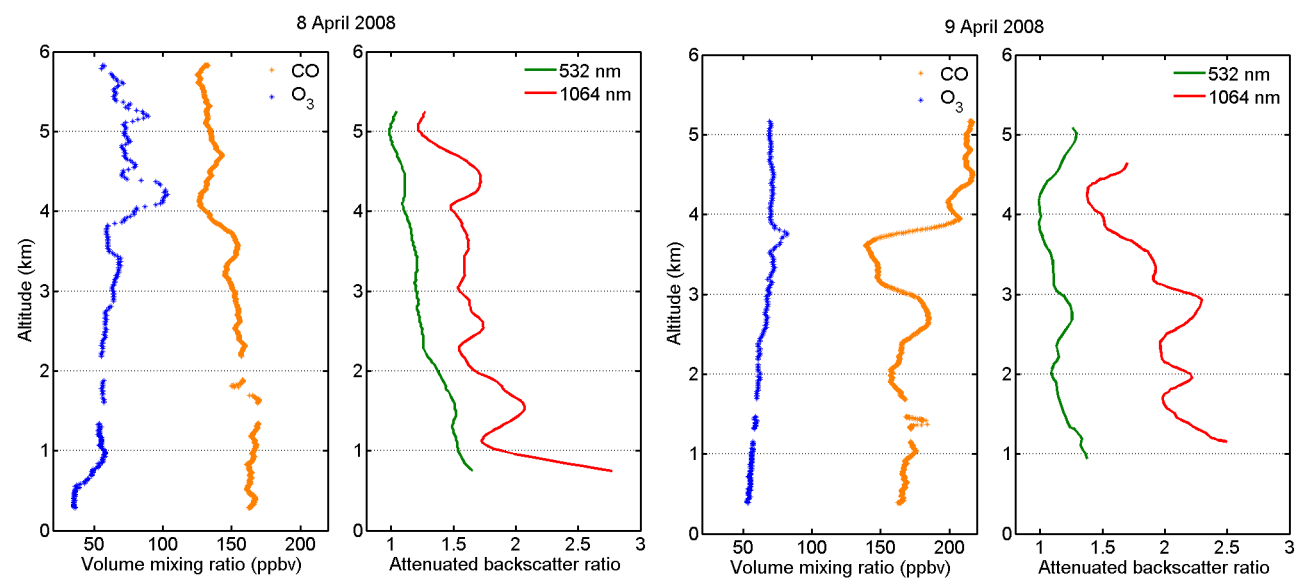

Fig. 13. Ozone and $\mathrm{CO}$ in situ measurements together with lidar total attenuated backscatter ratio during the two soundings. On the second one (9 April 2008) a layer with enhanced $\mathrm{CO}$ above $3.7 \mathrm{~km}$ indicates pollution transport.

The same holds true for the second flight, indicating that an assumed lognormal probability density function (pdf) for the distribution of extinctions is well suited.

A drawback of the logarithmic retrieval scheme with respect to the linear one is a slower convergence, it generally takes five iterations for the former as compared to two for the latter. This may come from a smaller degree of linearity in the logarithmic statement of Eq. (2) as mentioned by Schneider et al. (2006) for water vapor retrievals from ground-based infrared spectra. A second limitation comes with a likely underestimation of the errors, when the retrieved extinction is low, e.g., for altitude above $5 \mathrm{~km}$ (see Fig. 10). This is due to the logarithmic behavior toward small values (see Sect. 3.2). Indeed, in Figs. 10, 11 and 12, error bars correspond to the square root of the diagonal elements of the total error covariance matrix. Converting a logarithmic error covariance $\left(\mathbf{S}_{\mathbf{l n x}}\right)$ to a linear one $\left(\mathbf{S}_{\mathbf{x}}\right)$ often implies a Taylor expansion leading to the simple expression $\mathbf{S}_{\mathbf{x}}=\mathbf{x} \mathbf{S}_{\mathbf{x}} \mathbf{x}$, as detailed in (Dubovik et al., 1995). It is clear from this expression that for small values the associated covariance is small. In our case, we do not apply the Taylor expansion and use the exponential of the logarithmic error, but the problem is the same. These problems and a more detailed analysis of what the lognormal assumption can bring to the extinction retrieval from DOAS measurements deserve further attention, but this is outside the scope of this paper.

Figure 11 shows the retrievals of the vertical distribution of the $\mathrm{NO}_{2}$ concentration during the same sounding on 8 April 2008. In this case, the linear and logarithmic approaches yield similar results. The averaging kernels indicate a fairly constant sensitivity for the whole sounding with typical DOFS of 5.3 and 5.7 for the linear/logarithmic case. Three zones are distinguishable: (a) the boundary layer with a $\mathrm{NO}_{2}$ concentration of $1.9 \pm 0.3 \times 10^{9}$ molec $\mathrm{cm}^{-3}$, (b) the lower free troposphere with around $3 \pm 1 \times 10^{8} \mathrm{molec}^{-3}$ be- tween 1 and $4 \mathrm{~km}$ altitude and (c) the higher troposphere with negligible concentrations. In the boundary layer the corresponding $\mathrm{NO}_{2}$ volume mixing ratio is $66 \pm 19$ pptv, well above the detection limit of $40 \mathrm{pptv}$ calculated in the previous section. No in situ measurements are available for comparison but integrating the profile leads to a tropospheric column of $1.99 \times 10^{14}$ molec $\mathrm{cm}^{-2}$. The OMI tropospheric column extracted from the DOMINO product at the sounding time above the area is $1.705 \pm 6.146 \times 10^{14} \mathrm{molec} \mathrm{cm}^{-2}$. This value is close to our measurement but it lies inside its own error bars, which indicates that such low $\mathrm{NO}_{2}$ concentrations can barely be detected by OMI.

Figure 12 presents the extinction and $\mathrm{NO}_{2}$ retrievals for the sounding at $70^{\circ} \mathrm{N} 17.8^{\circ} \mathrm{E}$ on 9 April 2008. The radiative transfer was complicated by clouds close to the surface, so our retrievals start at $3 \mathrm{~km}$ altitude. We use the logarithmic case for the extinction retrieval. The DOFS value is low (0.27) but nevertheless the retrieved profile is distinctly different from the a priori and exhibits an extinction maximum, $0.025 \pm 0.005 \mathrm{~km}^{-1}$ at $4 \mathrm{~km}$ altitude, which is also visible in the extinction calculated from the size distribution. A maximum in the $\mathrm{NO}_{2}$ concentration of $1.95 \pm 0.2 \times 10^{9} \mathrm{molec} \mathrm{cm}^{-3}$ is also observed at the same altitude. For this $\mathrm{NO}_{2}$ retrieval, the DOFS value is 1.44.

\section{Interpretation of the retrieved profiles}

Figure 13 shows in situ measurements of ozone and CO during the two soundings studied here, together with total attenuated backscatter ratio $(R)$ measured with the lidar at 532 and $1064 \mathrm{~nm}$. This quantity, described in de Villiers et al. (2010, Appendix A), tends to unity when aerosol loading decreases. For the second sounding, the lidar profile was measured above $69.6^{\circ} \mathrm{N}, 19^{\circ} \mathrm{E}$ around 11:40 UTC i.e. two hours and $60 \mathrm{~km}$ off our sounding mainly since later the cloud cover 

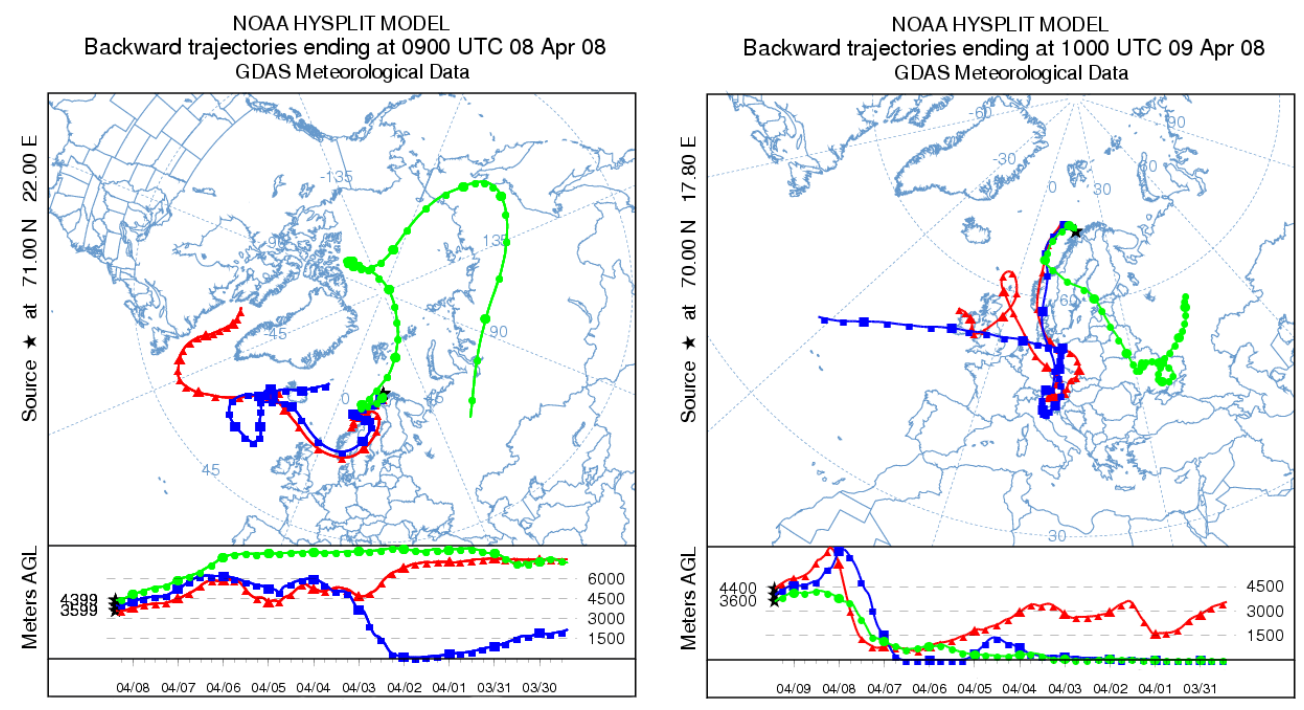

Fig. 14. Back-trajectories for the two soundings' positions calculated for altitudes of 3.6, 4 and $4.4 \mathrm{~km}$. During flight as0833 (9 April 2008 ), the air masses are clearly influenced by polluted zones, i.e. the boundary layer in central Europe.

mentioned in the previous section prevented a co-located measurement. $\mathrm{CO}$ can serve as a pollution tracer due to its long life time (around 20 days in the free troposphere Forster et al., 2001) and has both anthropogenic and natural sources, many of them correlated to the sources of $\mathrm{NO}_{2}$ and aerosols. The first sounding (8 April 2008) exhibits anticorrelated variations of ozone and $\mathrm{CO}$ volume mixing ratio (vmr) around the altitude where we measure an extinction enhancement in the free troposphere. The layer around $3.7 \mathrm{~km}$ altitude shows an increase of $15 \mathrm{ppbv} \mathrm{CO}$ over the level at $3 \mathrm{~km}$ altitude ( $150 \mathrm{ppbv})$; this corresponds to a reduction of ozone of the same order of magnitude. At $4.2 \mathrm{~km}$ altitude, the situation is opposite: a layer with higher ozone vmr ( $40 \mathrm{ppbv}$ over the level of $3 \mathrm{~km}$ altitude) corresponds to a $25 \mathrm{ppbv}$ reduction of $\mathrm{CO}$ vmr. Above $4.5 \mathrm{~km}$ altitude, weaker structures are still visible in the ozone profile. The lidar profile clearly shows the boundary layer, with $R$ values for $1064 \mathrm{~nm}$ of 2.8 at $0.8 \mathrm{~km}$ altitude, and other layers in the free troposphere, in particular at $4.3 \mathrm{~km}$ altitude, where $\mathrm{R}$ is around 1.8 . During the second sounding (9 April 2008), ozone is increasing smoothly from 50 to 60 ppbv with height, but $\mathrm{CO}$ presents two layers with enhanced vmr, around $2.7 \mathrm{~km}(+35 \mathrm{ppbv})$ and from $3.5 \mathrm{~km}$ to $5 \mathrm{~km}(+50 \mathrm{ppbv})$. These layers are correlated with enhancement of the $R$ values (respectively 2.3 and 1.8)

Anticorrelations between higher ozone concentration and $\mathrm{CO}$ have been observed in previous aircraft measurements (Koike et al. (1997) Zahn et al. (2000), Stohl et al., 2007). They have been explained by a stratospheric origin of the observed air or mixing with stratospheric air. The extinction layer around $4 \mathrm{~km}$ detected by our measurement during the first sounding is unlikely to come from the stratosphere since the background extinction observed is one order of magni- tude smaller (Vanhellemont et al., 2010) and no major volcanic eruptions were reported before the period of the campaign. From the lidar profile, it is not obvious if the structure at $3.7 \mathrm{~km}$ altitude with higher $\mathrm{CO}$ corresponds to our extinction maximum. Indeed, this is probably at the altitude of the $R$ maximum, $4.3 \mathrm{~km}$, even if it appears lower with the low vertical resolution of our retrieval achieved at this altitude, seen from the width of the averaging kernels in Fig. 10. On the second flight, the situation is clearer: a layer with high $\mathrm{CO}$ vmr and backscatter ratio occurs where our retrieved profiles of extinction and $\mathrm{NO}_{2}$ are maximum.

Figure 14 presents backward air mass trajectories for both flights calculated using the HYSPLIT (HYbrid SingleParticle Lagrangian Integrated Trajectory) model (Draxler and Hess, 1998) with the GDAS meteorological data serving as input. To understand the vertical variability around $4 \mathrm{~km}$ altitude in the two cases, the calculations start at 3.6, 4 and $4.4 \mathrm{~km}$ altitude for both soundings and consider a period of 10 days. HYSPLIT back trajectories calculated for the first sounding suggest a potential mixing of high and low altitude air masses: the air at $4 \mathrm{~km}$ appears to come from the boundary layer close to Iceland and is sandwiched between two air masses originating from higher up in the atmosphere. At $4.4 \mathrm{~km}$ height, the air originates from above the North pole and stayed mainly above $7 \mathrm{~km}$ altitude during the last 10 days, which agrees with the high measured ozone mixing ratios. The measurements of the first sounding can thus be explained by a mixing of stratospheric and boundary layer air masses. HYSPLIT results for the second sounding are again easier to interpret: the air mass at $4 \mathrm{~km}$ altitude originate from the central European boundary layer, where it has been lifted two days before the measurements. 


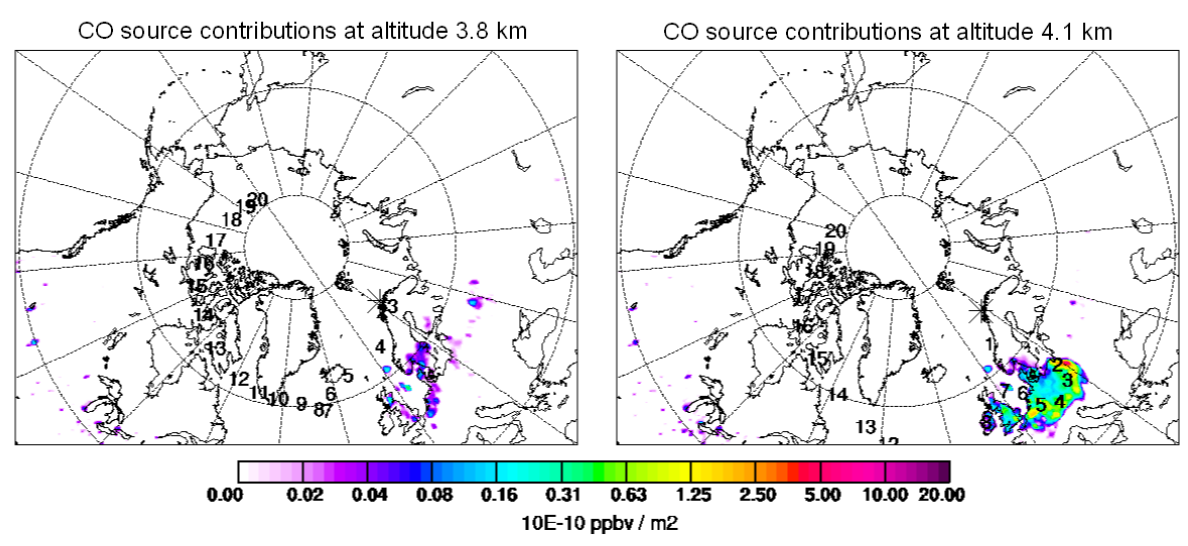

Total mixing ratio: $8.7 \mathrm{ppbv}$

Total mixing ratio: $57.1 \mathrm{ppbv}$

American: $2.0 \mathrm{ppbv}$ European: $5.2 \mathrm{ppbv}$ Asian: $1.6 \mathrm{ppbv}$ American: $2.6 \mathrm{ppbv}$ European: $54.1 \mathrm{ppbv}$ Asian: $0.3 \mathrm{ppbv}$

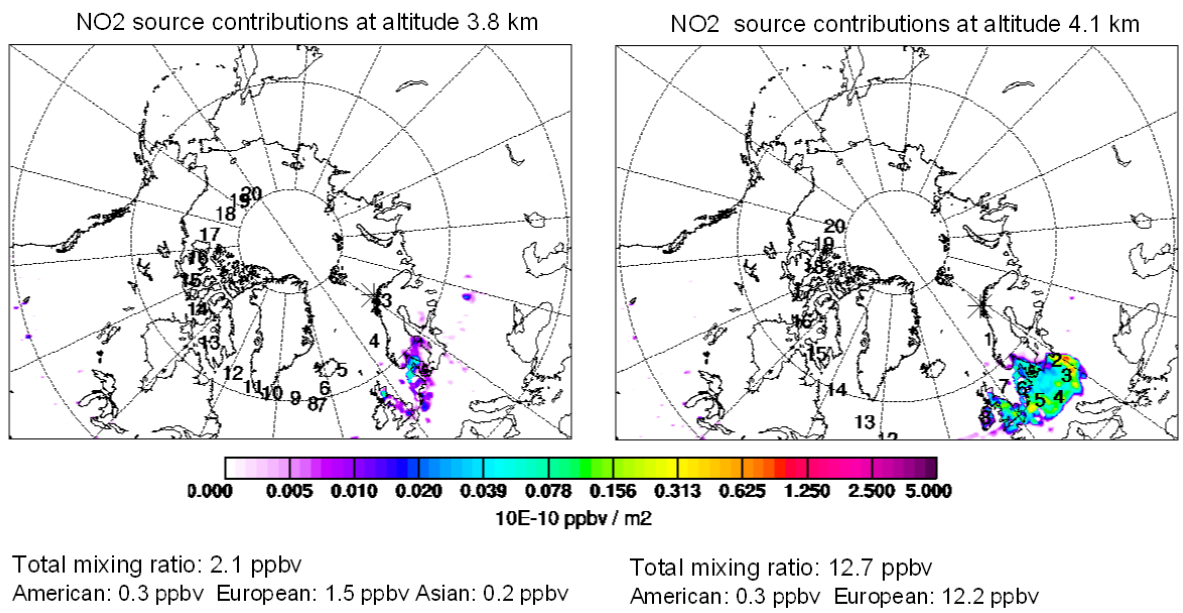

Fig. 15. $\mathrm{CO}$ and $\mathrm{NO}_{2}$ source contributions for the altitude with maximum $\mathrm{CO}$ concentration in the two soundings. Europe appears the dominant source and its influence is much larger on the second sounding (9 April 2008).

This back-trajectory explains the more polluted air mass of the second flight in the free troposphere, with higher $\mathrm{CO}$ and aerosol extinction, compared to the corresponding air mass in the first sounding.

The presence of the short-lived $\mathrm{NO}_{\mathrm{x}}$ in the Arctic is usually explained by peroxyacetic nitric anhydride (PAN) decomposition (Stroud et al., 2003), from local sources like ships (Wittrock et al., 2004) or snow photochemistry (Honrath et al., 1999). The back-trajectories of Fig. 14 tend to eliminate the last two options for the free tropospheric $\mathrm{NO}_{2}$ observed during the second flight. The air does not come from a close marine or snow-covered boundary layer. Considering PAN decomposition, which occurs mostly in summer (Beine and Krognes, 2000), the temperature at the altitude of the detected layer, $255 \mathrm{~K}$ is too low for it to be significant (Stroud et al., 2003). These considerations and the correlations between the $\mathrm{CO}$, aerosol extinction and $\mathrm{NO}_{2}$ layer suggest that this $\mathrm{NO}_{2}$ was directly transported from pollu- tion source regions in Europe. The lifetime of $\mathrm{NO}_{2}$ depends on the meteorological conditions, its main diurnal sink being the reaction with $\mathrm{OH}$, and at night, the hydrolysis of $\mathrm{N}_{2} \mathrm{O}_{5}$ on aerosols (Evans and Jacob, 2005). This lifetime can however be approximated by a decreasing exponential depending on the surrounding air mass temperature. According to the study of Dils (2008), this lifetime is 2.14 days with an in situ temperature of $255 \mathrm{~K}$. This result is close to the lifetime of $\mathrm{NO}_{\mathrm{x}}$ presented in Stroud et al. (2003), which is above 2.5 days. The back-trajectory of the second flight indicates that the air mass was in a polluted boundary layer 2 days before the measurement, which supports the idea of transported $\mathrm{NO}_{2}$.

We also ran the Lagrangian Particle Dispersion Model (LPDM) FLEXPART version 8 (Stohl et al., 2005) 20 days backward from short segments along all campaign flights (see http://transport.nilu.no/flexpart-projects?cmp= POLARCAT_FRANCE). The output of these calculations are emission sensitivities (Stohl et al., 2003), which can be 


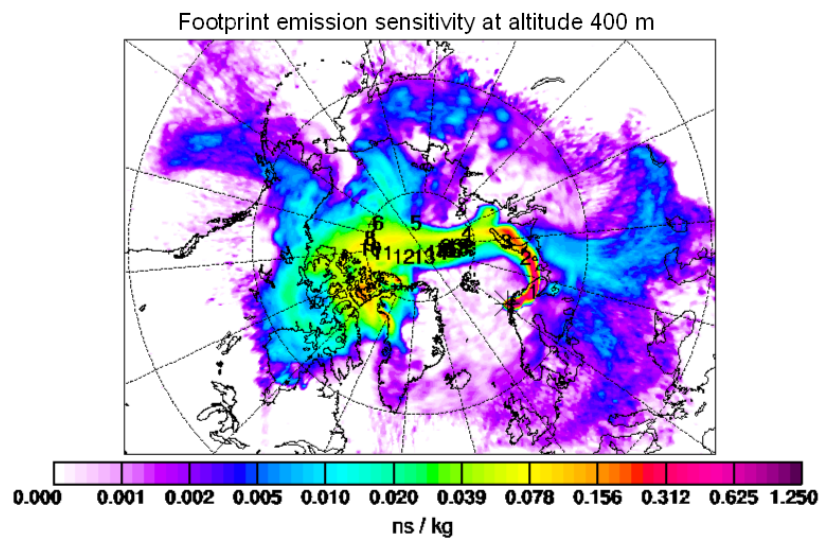

Fig. 16. Footprint emission sensitivity for the air in the boundary layer of the 8 April 2008 sounding, where enhanced $\mathrm{NO}_{2}$ is measured.

used to interpret transport processes and to identify potential pollution source regions. When ignoring removal processes and multiplying the emission sensitivities with emission flux densities of $\mathrm{CO}$ and $\mathrm{NO}_{\mathrm{x}}$, we obtain maps of source contributions, identifying the areas where pollution sources contributed to the sampled air mass. The emission data was taken from the EDGAR v32 database (Olivier et al., 2005) globally but EMEP emissions were used for Europe. Browsing the source contributions along the soundings, local maxima are found for the $\mathrm{CO}$ source contributions close to the altitude where the in situ sounding vmr are the largest. For the second flight, the $\mathrm{NO}_{2}$ source contribution is maximal at $4 \mathrm{~km}$ altitude. According to Fig. $15, \mathrm{NO}_{2}$ is released in the same regions as $\mathrm{CO}$, namely over Europe, especially over Poland. The total simulated CO mixing ratio of $57 \mathrm{ppbv}$ accumulated for 20 days prior to the sounding is close to the measured CO enhancement over the background. During the first flight, the simulated $\mathrm{CO}$ tracer enhancement is less than 9 ppbv, in agreement with the small measured $\mathrm{CO}$ enhancements. In this case, CO sources located in Northwestern Europe are responsible for the detected $\mathrm{CO}$ enhancement. Notice that the simulated total $\mathrm{NO}_{2}$ tracer measurements are much larger than the measured $\mathrm{NO}_{2}$, because the model accumulates emissions over 20 days without considering removal processes. In reality, only a fraction of the $\mathrm{NO}_{\mathrm{x}}$ emitted over the last 20 days is transported to the measurement location and only a fraction of it is present as $\mathrm{NO}_{2}$.

Considering the boundary layer $\mathrm{NO}_{2}$ observed during the first flight, footprint emission sensitivities shown in Fig. 16 indicate that the surface areas influencing the air mass are Northern Lapland, parts of the Kola peninsula and Barents Sea. While FLEXPART does not indicate a large $\mathrm{CO}$ or $\mathrm{NO}_{2}$ source contribution from these areas, transport times from the Kola Peninsula were less than 1 day and even the small (1 ppbv) simulated $\mathrm{NO}_{2}$ tracer mixing ratio (originat- ing mostly from the Kola Peninsula) is much larger than the measured $\mathrm{NO}_{2}$ mixing ratio. Furthermore, emissions on the Kola Peninsula are notably uncertain, with known errors in the emission inventories. In particular, NOx emissions transported from Nikel which is located on the western Kola Peninsula are apparently too low and appear erroneously attributed in the inventories to emissions of Murmansk (Prank et al., 2010). Emissions from the smelters are sulfur-rich, so that it is likely that the observed aerosols are mainly sulfate. The smelter emissions are relatively poor in $\mathrm{CO}$, so the small measured $\mathrm{CO}$ enhancements are not contradictory to this source.

\section{Conclusions}

We have retrieved vertical distributions of the aerosol extinction coefficient and $\mathrm{NO}_{2}$ concentration using a recently developed airborne DOAS instrument flown on board the ATR42 during the POLARCAT-France campaign in spring 2008 between continental Norway and Svalbard. The instrument recorded scattered skylight spectra at the horizon, in which $\mathrm{NO}_{2}$ and $\mathrm{O}_{4}$ absorption structures were identified. The latter were used to infer aerosol extinction profiles at $360 \mathrm{~nm}$, which were included in the $\mathrm{NO}_{2}$ profile retrievals. The results were then interpreted using ancillary in situ chemical measurements and transport models back-trajectories.

For a sounding performed on 8 April 2008, the retrieved extinction is $0.04 \pm 0.005 \mathrm{~km}^{-1}$ in the boundary layer and a smaller extinction layer $\left(0.01 \pm 0.003 \mathrm{~km}^{-1}\right)$ appears at 4 $\mathrm{km}$ altitude. $\mathrm{NO}_{2}$ is also present in the boundary layer, its retrieved concentration being $1.9 \pm 0.3 \times 10^{9}$ molec cm$^{-3}$. For a sounding performed on the 9 April 2008, a layer with enhanced extinction and $\mathrm{NO}_{2}$ was detected at $4 \mathrm{~km}$ altitude, with respective values of $0.025 \pm 0.005 \mathrm{~km}^{-1}$ and $1.95 \pm 0.2 \times 10^{9}$ molec cm $^{-3}$.

For both soundings, the extinctions inferred for the free troposphere match layers of enhanced $\mathrm{CO}$ which indicates pollution transport. The magnitudes are however very different. The small extinction detected in the first sounding is explained from back-trajectories indicating a mixture of stratospheric air and polluted air transported from Northwestern Europe, whereas for the second sounding the air masses originated mostly from central Europe. The aerosols and $\mathrm{NO}_{2}$ seen in the boundary layer during the first flight seem to originate from metal smelters and industry near Nikel on the Kola peninsula. The $\mathrm{NO}_{2}$ layer at $4 \mathrm{~km}$ altitude observed during the second flight seems to have been directly transported from central Europe with the $\mathrm{CO}$ and aerosols.

The instrument and the inversion method successfully fulfilled the scientific objectives of the study, yielding quantitative insights into the chemical composition and aerosol content of the Arctic troposphere, with a vertical resolution unachievable from ground or satellite, especially in the free troposphere. The logarithmic approach used for the aerosol 
extinction, which yielded better agreement with ancillary data in the two studied cases, should be further investigated as it could also improve ground-based retrievals. The experiment could be repeated in other areas to measure profiles of all species potentially detectable with the DOAS technique in our spectrometer spectral range. The high sensitivity could be further increased by adding a feedback on the scanning telescope to maintain it parallel to the horizon. We believe interesting future applications could concern molecules for which fewer observations are available, such as IO which deserves further investigations due to its importance in ozone chemistry.

Acknowledgements. This work was supported by the Belgian Federal Science Policy (contract MO/35/028). POLARCAT-France was funded by French ANR, CNES, CNRS-INSU (LEFE-CHAT), IPEV and EUFAR, the latter funded also our participation to the campaign and a couple of additional flight hours. We are grateful to the UMS SAFIRE for their support in the instrument installation and providing the aircraft data. We also thank colleagues Corinne Vigouroux, François Hendrick, Emmanuel Dekemper, Valentin Duflot, Filip Vanhellemont and Rachel Drummond for interesting discussions on the data analysis.

Edited by: J. W. Bottenheim

\section{References}

Ancellet, G., Leclair de Bellevue, J., Mari, C., Nedelec, P., Kukui, A., Borbon, A., and Perros, P.: Effects of regional-scale and convective transports on tropospheric ozone chemistry revealed by aircraft observations during the wet season of the AMMA campaign, Atmos. Chem. Phys., 9, 383-411, doi:10.5194/acp-9-3832009, 2009.

Beine, H. J. and Krognes, T.: The seasonal cycle of peroxyacetyl nitrate (PAN) in the European Arctic, Atmos. Environ., 34, 933940, doi:10.1016/S1352-2310(99)00288-5, 2000.

Boersma, K. F., Eskes, H. J., Veefkind, J. P., Brinksma, E. J., van der A, R. J., Sneep, M., van den Oord, G. H. J., Levelt, P. F., Stammes, P., Gleason, J. F., and Bucsela, E. J.: Near-real time retrieval of tropospheric $\mathrm{NO}_{2}$ from OMI, Atmos. Chem. Phys., 7, 2103-2118, doi:10.5194/acp-7-2103-2007, 2007.

Bogumil, K., Orphal, J., Homann, T., Voigt, S., Spietz, P., Fleischmann, O., Vogel, A., Hartmann, M., Kromminga, H., Bovensmann, H., Frerick, J., and Burrows, J.: Measurements of molecular absorption spectra with the SCIAMACHY pre-flight model: instrument characterization and reference data for atmospheric remote-sensing in the $230-2380 \mathrm{~nm}$ region, J. Photoch. Photobio. A., 157, 167-184, 2003.

Bond, T. C., Habib, G., and Bergstrom, R. W.: Limitations in the enhancement of visible light absorption due to mixing state, J. Geophys. Res., 111, doi:10.1029/2006JD007315, 2006.

Brandt, R. E., Warren, S. G., Worby, A. P., and Grenfell, T. C.: Surface Albedo of the Antarctic Sea Ice Zone, J. Climate, 18, 3606-3622, doi:10.1175/JCLI3489.1, 2005.

Bruns, M., Buehler, S. A., Burrows, J. P., Richter, A., Rozanov, A., Wang, P., Heue, K. P., Platt, U., Pundt, I., and Wagner, T.: $\mathrm{NO}_{2}$
Profile retrieval using airborne multi axis UV-visible skylight absorption measurements over central Europe, Atmos. Chem. Phys., 6, 3049-3058, doi:10.5194/acp-6-3049-2006, 2006.

Chance, K. V. and Spurr, R. J. D.: Ring effect studies: Rayleigh scattering, including molecular parameters for rotational Raman scattering, and the Fraunhofer spectrum, Appl. Optics, 36, 52245230, doi:10.1364/AO.36.005224, 1997.

Clémer, K., Van Roozendael, M., Fayt, C., Hendrick, F., Hermans, C., Pinardi, G., Spurr, R., Wang, P., and De Mazière, M.: Multiple wavelength retrieval of tropospheric aerosol optical properties from MAXDOAS measurements in Beijing, Atmos. Meas. Tech., 3, 863-878, doi:10.5194/amt-3-863-2010, 2010.

de Villiers, R. A., Ancellet, G., Pelon, J., Quennehen, B., Schwarzenboeck, A., Gayet, J. F., and Law, K. S.: Airborne measurements of aerosol optical properties related to early spring transport of mid-latitude sources into the Arctic, Atmos. Chem. Phys., 10, 5011-5030, doi:10.5194/acp-10-5011-2010, 2010.

Deeter, M. N., Edwards, D. P., and Gille, J. C.: Retrievals of carbon monoxide profiles from MOPITT observations using lognormal a priori statistics, J. Geophys. Res., 112, 9 pp., doi:10.1029/2006JD007999, 2007.

Dils, B.: Long Range Transport of Tropospheric NO2 as simulated by FLEXPART, Product Specification Document TEM/LRT2/001, TEMIS, De Bilt, The Netherlands, 2008.

Dubovik, O. V., Lapyonok, T. V., and Oshchepkov, S. L.: Improved technique for data inversion: optical sizing of multicomponent aerosols, Appl. Opt., 34, 8422-8436, doi:10.1364/AO.34.008422, 1995.

Evans, M. J. and Jacob, D. J.: Impact of new laboratory studies of N2O5 hydrolysis on global model budgets of tropospheric nitrogen oxides, ozone, and $\mathrm{OH}$, Geophys. Res. Lett., 32, doi:10.1029/2005GL022469, 2005.

Fayt, C., De Smedt, I., Letocart, V., Merlaud, A., Pinardi, G., and Van Roozendael, M.: QDOAS, Software User Manual, Belgian Insitute for Space Aeronomy, Brussels, Belgium, 2011.

Forster, C., Wandinger, U., Wotawa, G., James, P., Mattis, I., Althausen, D., Simmonds, P., O’Doherty, S., Jennings, S. G., Kleefeld, C., Schneider, J., Trickl, T., Kreipl, S., Jäger, H., and Stohl, A.: Transport of boreal forest fire emissions from Canada to Europe, J. Geophys. Res., 106, 22887-22906, doi:10.1029/2001JD900115, 2001.

Friess, U., Monks, P. S., Remedios, J. J., Rozanov, A., Sinreich, R., Wagner, T., and Platt, U.: MAX-DOAS O4 measurements: A new technique to derive information on atmospheric aerosols: 2. Modeling studies, J. Geophys. Res., 111, doi:10.1029/2005JD006618, 2006.

Grainger, J. F. and Ring, J.: Anomalous Fraunhofer Line Profiles, Nature, 193, doi:10.1038/193762a0, 1962.

Granier, C., Niemeier, U., Jungclaus, J. H., Emmons, L., Hess, P., Lamarque, J., Walters, S., and Brasseur, G. P.: Ozone pollution from future ship traffic in the Arctic northern passages, Geophys. Res. Lett., 33, doi:10.1029/2006GL026180, 2006.

Harder, J. W. and Brault, J. W.: Atmospheric measurements of water vapor in the 442-nm region, J. Geophys. Res., 102, 62456252, doi:10.1029/96JD01730, 1997.

Hendrick, F., Van Roozendael, M., Kylling, A., Petritoli, A., Rozanov, A., Sanghavi, S., Schofield, R., von Friedeburg, C., Wagner, T., Wittrock, F., Fonteyn, D., and De Mazire, M.: Intercomparison exercise between different radiative transfer mod- 
els used for the interpretation of ground-based zenith-sky and multi-axis DOAS observations, Atmos. Chem. Phys., 6, 93-108, doi:10.5194/acp-6-93-2006, 2006.

Herber, A., Thomason, L. W., Gernandt, H., Leiterer, U., Nagel, D., Schulz, K., Kaptur, J., Albrecht, T., and Notholt, J.: Continuous day and night aerosol optical depth observations in the Arctic between 1991 and 1999, 2002.

Hess, M., Koepke, P., and Schult, I.: Optical Properties of Aerosols and Clouds: The Software Package OPAC, B. Am. Meteorol. Soc., 79, 831-844, 1998.

Hönninger, G., von Friedeburg, C., and Platt, U.: Multi axis differential optical absorption spectroscopy (MAX-DOAS), Atmos. Chem. Phys., 4, 231-254, doi:10.5194/acp-4-231-2004, 2004.

Honrath, R. E., Peterson, M. C., Guo, S., Dibb, J. E., Shepson, P. B., and Campbell, B.: Evidence of NOx production within or upon ice particles in the Greenland snowpack, Geophys. Res. Lett., 26, 695-698, doi:10.1029/1999GL900077, 1999.

Irie, H., Kanaya, Y., Akimoto, H., Iwabuchi, H., Shimizu, A., and Aoki, K.: First retrieval of tropospheric aerosol profiles using MAX-DOAS and comparison with lidar and sky radiometer measurements, Atmos. Chem. Phys., 8, 341-350, doi:10.5194/acp-8341-2008, 2008.

Koike, M., Kondo, Y., Kawakami, S., Nakajima, H., Gregory, G. L., Sachse, G. W., Singh, H. B., Browell, E. V., Merrill, J. T., and Newell, R. E.: Reactive nitrogen and its correlation with $\mathrm{O}_{3}$ and $\mathrm{CO}$ over the Pacific in winter and early spring, J. Geophys. Res., 102, doi:10.1029/97JD02085, 1997.

Law, K. and Stohl, A.: Arctic Air Pollution: Origins and Impacts, Science, 315, 1537-1540, doi:10.1126/science.1137695, 2007.

Levelt, P., van den Oord, G., Dobber, M., Malkki, A., Visser, H., de Vries, J., Stammes, P., Lundell, J., and Saari, H.: The ozone monitoring instrument, IEEE T. Geosci. Remote., 44, doi:10.1109/TGRS.2006.872333, 2006.

Mätzler, C.: Matlab functions for Mie scattering and absorption, Research report no. 2002-08, Institut für Angewandte Physik, Bern, 2002.

Mayer, B. and Kylling, A.: Technical note: The libRadtran software package for radiative transfer calculations - description and examples of use, Atmos. Chem. Phys., 5, 1855-1877, doi:10.5194/acpd-5-1319-2005, 2005.

McPeters, R. D., Labow, G. J., and Logan, J. A.: Ozone climatological profiles for satellite retrieval algorithms, J. Geophys. Res., 112, doi:10.1029/2005JD006823, 2007.

Mount, G. H., Rusch, D. W., Noxon, J. F., Zawodny, J. M., and Barth, C. A.: Measurements of Stratospheric $\mathrm{NO}_{2}$ From the Solar Mesosphere Explorer Satellite 1. An Overview of the Results, J. Geophys. Res., 89, 1327-1340, doi:10.1029/JD089iD01p01327, 1984.

Nédélec, P., Cammas, J.-P., Thouret, V., Athier, G., Cousin, J.-M., Legrand, C., Abonnel, C., Lecoeur, F., Cayez, G., and Marizy, C.: An improved infrared carbon monoxide analyser for routine measurements aboard commercial Airbus aircraft: technical validation and first scientific results of the MOZAIC III programme, Atmos. Chem. Phys., 3, 1551-1564, doi:10.5194/acp-3-15512003, 2003.

Olivier, J., Aardenne, J. V., Dentener, F., Pagliari, V., Ganzeveld, L., and Peters, J.: Recent trends in global greenhouse gas emissions: regional trends 1970-2000 and spatial distribution of key sources in 2000, Env. Sc., 2, 81-99, doi:10.1080/15693430500400345,
2005.

Platt, U. and Stutz, J.: Differential Optical Absorption Spectroscopy: Principles and Applications, Physics of Earth and Space Environments, Springer, Berlin, 2008.

Prados-Roman, C., Butz, A., Deutschmann, T., Dorf, M., Kritten, L., Minikin, A., Platt, U., Schlager, H., Sihler, H., Theys, N., Van Roozendael, M., Wagner, T., and Pfeilsticker, K.: Airborne DOAS limb measurements of tropospheric trace gas profiles: case studies on the profile retrieval of $\mathrm{O}_{4}$ and $\mathrm{BrO}$, Atmos. Meas. Tech., 4, 1241-1260, doi:10.5194/amt-4-1241-2011, 2011.

Prank, M., Sofiev, M., Denier van der Gon, H. A. C., Kaasik, M., Ruuskanen, T. M., and Kukkonen, J.: A refinement of the emission data for Kola Peninsula based on inverse dispersion modelling, Atmos. Chem. Phys., 10, 10849-10865, doi:10.5194/acp10-10849-2010, 2010.

Ridley, B., Walega, J., Montzka, D., Grahek, F., Atlas, E., Flocke, F., Stroud, V., Deary, J., Gallant, A., Boudries, H., Bottenheim, J., Anlauf, K., Worthy, D., Sumner, A. L., Splawn, B., and Shepson, P.: Is the Arctic Surface Layer a Source and Sink of $\mathrm{NO}_{\mathrm{x}}$ in Winter/Spring?, J. Atmos. Chem., 36, 1-22, doi:10.1023/A:1006301029874, 2000.

Rodgers, C. D.: Inverse Methods for Atmospheric Sounding : Theory and Practice, World Scientific Publishing Company, 2000.

Schneider, M., Hase, F., and Blumenstock, T.: Water vapour profiles by ground-based FTIR spectroscopy: study for an optimised retrieval and its validation, Atmos. Chem. Phys., 6, 811-830, doi:10.5194/acp-6-811-2006, 2006.

Shaw, G. E.: The Arctic Haze Phenomenon, B. Am. Meteorol. Soc., 76, 2403-2414, doi:10.1175/1520-

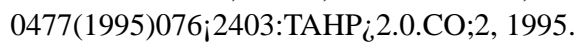

Stohl, A., Forster, C., Eckhardt, S., Spichtinger, N., Huntrieser, H., Heland, J., Schlager, H., Wilhelm, S., Arnold, F., and Cooper, O.: A backward modeling study of intercontinental pollution transport using aircraft measurements, J. Geophys. Res., 108, 18 pp., doi:10.1029/2002JD002862, http://www.agu.org/journals/ABS/ 2003/2002JD002862.shtml, 2003.

Stohl, A., Forster, C., Frank, A., Seibert, P., and Wotawa, G.: Technical note: The Lagrangian particle dispersion model FLEXPART version 6.2, Atmos. Chem. Phys., 5, 2461-2474, doi:10.5194/acp-5-2461-2005, 2005.

Stohl, A., Forster, C., Huntrieser, H., Mannstein, H., McMillan, W. W., Petzold, A., Schlager, H., and Weinzierl, B.: Aircraft measurements over Europe of an air pollution plume from Southeast Asia - aerosol and chemical characterization, Atmos. Chem. Phys., 7, 913-937, doi:10.5194/acp-7-913-2007, 2007.

Stroud, C., Madronich, S., Atlas, E., Ridley, B., Flocke, F., Weinheimer, A., Talbot, B., Fried, A., Wert, B., Shetter, R., Lefer, B., Coffey, M., Heikes, B., and D., B.: Photochemistry in the arctic free troposphere: $\mathrm{NO}_{\mathrm{x}}$ budget and the role of odd nitrogen reservoir recycling, Atmos. Environ., 37, 3351-3364, doi:10.1016/S1352-2310(03)00353-4, 2003.

Tomasi, C., Vitale, V., Lupi, A., Carmine, C. D., Campanelli, M., Herber, A., Treffeisen, R., Stone, R. S., Andrews, E., Sharma, S., Radionov, V., von Hoyningen-Huene, W., Stebel, K., Hansen, G. H., Myhre, C. L., Wehrli, C., Aaltonen, V., Lihavainen, H., Virkkula, A., Hillamo, R., Ström, J., Toledano, C., Cachorro, V. E., Ortiz, P., de Frutos, A. M., Blindheim, S., Frioud, M., Gausa, M., Zielinski, T., Petelski, T., and Yamanouchi, T.: Aerosols in polar regions: A historical overview based on optical 
depth and in situ observations, J. Geophys. Res., 112, D16205, doi:10.1029/2007JD008432, 2007.

Vanhellemont, F., Fussen, D., Mateshvili, N., Tétard, C., Bingen, C., Dekemper, E., Loodts, N., Kyrölä, E., Sofieva, V., Tamminen, J., Hauchecorne, A., Bertaux, J.-L., Dalaudier, F., Blanot, L., Fanton d'Andon, O., Barrot, G., Guirlet, M., Fehr, T., and Saavedra, L.: Optical extinction by upper tropospheric/stratospheric aerosols and clouds: GOMOS observations for the period 20022008, Atmos. Chem. Phys., 10, 7997-8009, doi:10.5194/acp-107997-2010, 2010.

Villani, P., Picard, D., Michaud, V., Laj, P., and Wiedensohler, A.: Design and Validation of a Volatility Hygroscopic Tandem Differential Mobility Analyzer (VH-TDMA) to Characterize the Relationships Between the Thermal and Hygroscopic Properties of Atmospheric Aerosol Particles, Aerosol. Sci. Tech., 42, doi:10.1080/02786820802255668, 2008.

Wagner, T., Dix, B., Friedeburg, C. V., Friess, U., Sanghavi, S., Sinreich, R., and Platt, U.: MAX-DOAS O 4 measurements: A new technique to derive information on atmospheric aerosols: 1. Principles and information content, J. Geophys. Res., 109, D22205, doi:10.1029/2004JD004904, 2004.

Wagner, T., Burrows, J. P., Deutschmann, T., Dix, B., von Friedeburg, C., Frieß, U., Hendrick, F., Heue, K.-P., Irie, H., Iwabuchi, H., Kanaya, Y., Keller, J., McLinden, C. A., Oetjen, H., Palazzi, E., Petritoli, A., Platt, U., Postylyakov, O., Pukite, J., Richter, A., van Roozendael, M., Rozanov, A., Rozanov, V., Sinreich, R., Sanghavi, S., and Wittrock, F.: Comparison of box-airmass-factors and radiances for Multiple-Axis Differential Optical Absorption Spectroscopy (MAX-DOAS) geometries calculated from different UV/visible radiative transfer models, Atmos. Chem. Phys., 7, 1809-1833, doi:10.5194/acp-7-1809-2007, 2007.
Wittrock, F., Oetjen, H., Richter, A., Fietkau, S., Medeke, T., Rozanov, A., and Burrows, J.: MAX-DOAS measurements of atmospheric trace gases in Ny-Alesund - Radiative transfer studies and their application, Atmos. Chem. Phys., 4, 955-966, doi:10.5194/acp-4-955-2004, 2004.

Zahn, A., Brenninkmeijer, C. A. M., Maiss, M., Scharffe, D. H., Crutzen, P. J., Hermann, M., Heintzenberg, J., Wiedensohler, A., (Güsten), H., Heinrich, G., Fischer, H., Cuijpers, J. W. M., and van Velthoven, P. F. J.: Identification of extratropical two-way troposphere-stratosphere mixing based on CARIBIC measurements of $\mathrm{O}_{3}, \mathrm{CO}$, and ultrafine particles, J. Geophys. Res., 105, 1527-1535, doi:10.1029/1999JD900759, 2000.

Zhou, Y., Brunner, D., Boersma, K. F., Dirksen, R., and Wang, P.: An improved tropospheric $\mathrm{NO}_{2}$ retrieval for OMI observations in the vicinity of mountainous terrain, Atmos. Meas. Tech., 2, 401-416, doi:10.5194/amt-2-401-2009, 2009.

Zieger, P., Weingartner, E., Henzing, J., Moerman, M., de Leeuw, G., Mikkilä, J., Ehn, M., Petäjä, T., Clémer, K., van Roozendael, M., Yilmaz, S., Frieß, U., Irie, H., Wagner, T., Shaiganfar, R., Beirle, S., Apituley, A., Wilson, K., and Baltensperger, U.: Comparison of ambient aerosol extinction coefficients obtained from in-situ, MAX-DOAS and LIDAR measurements at Cabauw, Atmos. Chem. Phys. Discuss., 10, 29683-29734, doi:10.5194/acpd-10-29683-2010, 2010. 